The word count of this manuscript: 19586 words (including appendix, tables and figures)

\title{
Embodied Carbon in China's Foreign Trade: An Online SCI-E and SSCI Based Literature Review
}

Zhonghua Zhang ${ }^{\mathrm{a}, \mathrm{d}}$, Yuhuan Zhao ${ }^{\mathrm{a}, \mathrm{b}},{ }^{*}, \mathrm{Bin}_{\mathrm{Su}}^{\mathrm{d}, *}$, Yongfeng Zhang ${ }^{\mathrm{c}, \mathrm{a}}$, Song Wang ${ }^{\mathrm{a}}$, Ya Liu ${ }^{\mathrm{a}}$,

Hao $\mathrm{Li}^{\mathrm{a}}$

( ${ }^{a}$ School of Management and Economics, Beijing Institute of Technology, Beijing, 100081,

China;

${ }^{\mathrm{b}}$ Sustainable Development Research Institute for Economy and Society of Beijing, Beijing Institute of Technology, Beijing, 100081, China;

${ }^{\mathrm{c}}$ School of Economics and Management, Yanan University, Yanan, 716000, Shaanxi)

${ }^{\mathrm{d}}$ Energy Studies Institute, National University of Singapore, 119620, Singapore)

* Corresponding author. E-mail address:

zhaoyuhuan@bit.edu.cn (Yuhuan Zhao); subin@nus.edu.sg (Bin Su) 
Abstract: This paper systematically presents a survey of the empirical literature studying the embodied $\mathrm{CO}_{2}$ emissions in China's foreign trade (ECCT). Based on the bibliometric method and the online version of Science Citation Index-Expanded (SCI-E) and Social Sciences Citation Index (SSCI), this study summarizes the latest publications regarding ECCT in peer-reviewed journals in terms of quantities, most productive countries, institutions, authors, citations, and disciplines. By using synthetic analysis of keyword frequency, this study reveals the most popular methodologies applied in measuring ECCT, discusses the variation of numerical results in the literature, and reasons and countermeasures for the results uncertainties. Continuous investigation of the literature releases the methodology employed for measuring ECCT becoming more reasonable and the results more critical. However, the numerical results of ECCT are of great discrepancies within given year by different considerations on methodology specification, accounting principles, and data sources and processing. For instance, the estimates of $\mathrm{CO}_{2}$ embodied in China's exports changed from $478 \mathrm{Mt}$ to over 3,000 Mt and those of in China's imports ranged from $140 \mathrm{Mt}$ to over 1,700 Mt in 2007. Therefore, overcoming data inherent limitations and reducing discrepancies among available databases should be urgently considered. The results imply that the prospective research tendencies on ECCT are to (1) improve China's regional input-output data and energy intensity data to more precise estimates under global perspective; (2) estimate China's carbon emission at firm level by different firm ownerships in production and consumption worldwide; (3) assess China's carbon emission from processing or non-processing trade by compiling more detailed multi-regional inputoutput table; (4) evaluate city level carbon mitigation capacity in China under global MRIO model; (5) explore new carbon management experience in China's carbon trading market and new trade expansion policy of 'one belt and one road' in her new growth era.

Keywords: Climate change; Bibliometrics; Keyword frequency analysis; Embodied carbon; Foreign trade; China 


\section{Contents}

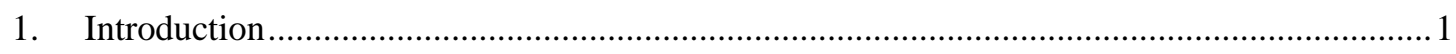

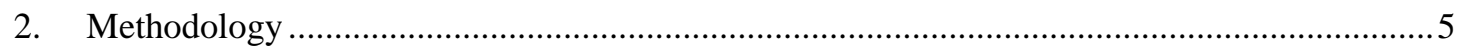

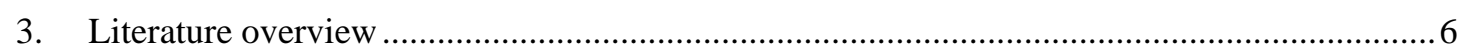

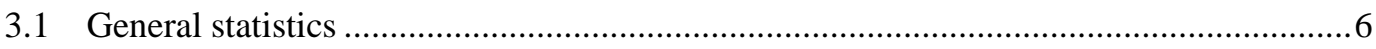

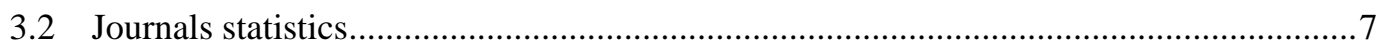

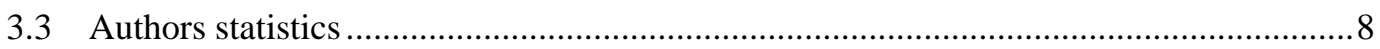

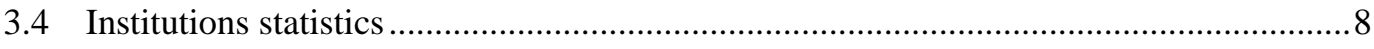

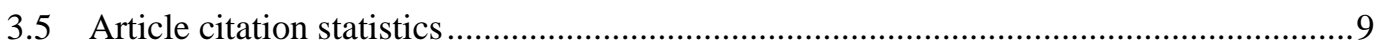

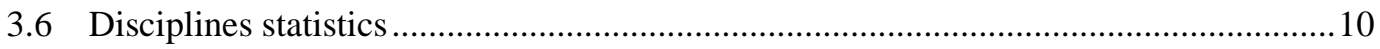

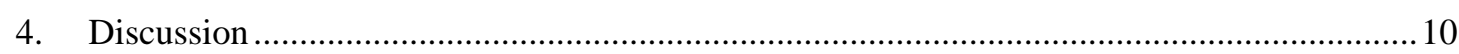

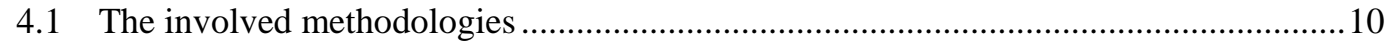

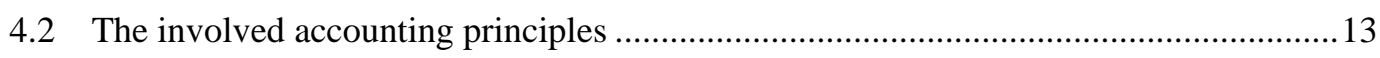

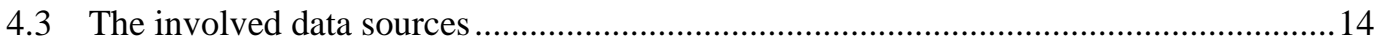

4.4 The quantitative results of ECCT from literature .........................................................15

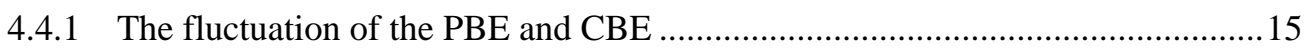

4.4.2 The fluctuation of the EEE and EEI.............................................................. 17

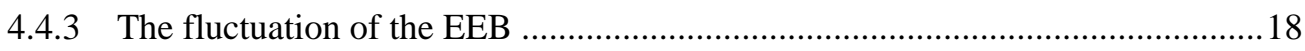

4.5 Reasons and countermeasures to the results uncertainty ............................................20

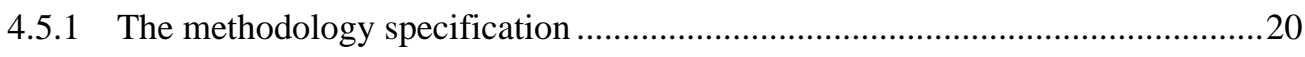

4.5.2 The accounting principle specification ........................................................22

4.5.3 The data source specification .....................................................................22

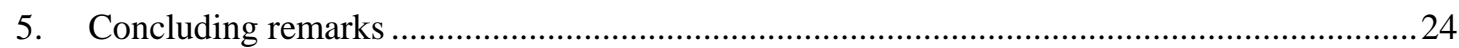

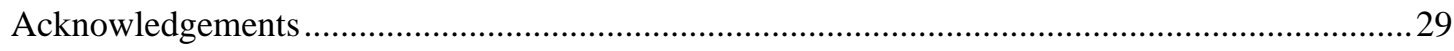

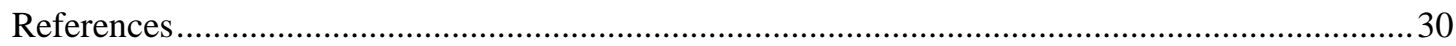




\section{Abbreviations and Definitions}

ECCT: Embodied $\mathrm{CO}_{2}$ emissions in China's foreign trade;

PBE: Production-based $\mathrm{CO}_{2}$ emissions;

CBE: Consumption-based $\mathrm{CO}_{2}$ emissions:

EEE: Embodied $\mathrm{CO}_{2}$ emissions in the exports from an economy;

EEI: Embodied $\mathrm{CO}_{2}$ emissions in the imports from an economy;

EEB: Balance of embodied $\mathrm{CO}_{2}$ emissions in international trade from an economy;

EE-IOA: Environmentally extended input-output analysis;

EEEP: Ratio of the EEE out of the PBE;

EEIP: Ratio of the EEI out of the PBE;

EEBP: Ratio of the EEB out of the PBE;

ETS: Emission trading system;

SCI-E: Science Citation Index-Expanded;

SSCI: Social Sciences Citation Index;

GVCs: Global value chains;

MT: Million tonnes;

SRIO: Single region input-output model;

BTIO: Bilateral trade input-output model;

MRIO: Multi-region input-output model;

CGE: Computable general equilibrium model;

SDA: Structural decomposition analysis;

IDA: Index decomposition analysis;

SPD: Structural path decomposition;

LCA: Life cycle analysis;

PA: Price adjustment method;

RME: Raw material equivalents;

PPP: Purchasing power parity;

MER: Market exchange rate; 


\section{Introduction}

Climate change has been widely recognized as the global major environmental issue. Whether the global warming is an anthropogenic phenomenon or not is impossible to justify nowadays. However, it is obvious that the atmosphere has been undergoing a tremendous surge of $\mathrm{CO}_{2}$ from the global industrialization. The anthropogenic greenhouse gases (GHGs) emissions are the main cause of global climate change according to Intergovernmental Panel on Climate Change (IPCC) [1, 2]. Embodied carbon in international trade plays a crucial role in international negotiation on global climate change [3]. With the research outputs expanding substantially in recent years, embodied carbon in China's foreign trade (ECCT) has attracted a growing attention globally. Although China's carbon emissions declined from 2013 because of many carbon mitigation implements recently [4], for example, China dropped 2 percent and 3 percent carbon emission in 2014 and 2015 respectively since 2001[5], being the top $\mathrm{CO}_{2}$ emitter with huge economy amounts and high growth rates [6], China still took up $23.43 \%$ of global $\mathrm{CO}_{2}$ emissions in 2014 [7]. Besides, China's coal consumption fell 2.9 percent and weakened by 3.8 percent in 2014 which is the lowest value since 1998 because of the expanding of Chinese economy at the slowest rate since 1990 [8]. Up to $90 \%$ of carbon emission were from fossil fuel combustion, in which coal took up over $60 \%$ in China, and over $85 \%$ of carbon emissions were produced by power generation and manufacturing sectors in $2012[9,10]$.

As an ambitious country in curbing carbon emission, China had pledged to achieve her peak of carbon emission around 2030 by reducing nearly $65 \%$ carbon intensity comparing to 2005 levels and made her best utmost to peak early. China also planned to raise the ratio of non-fossil fuels in primary energy to $20 \%$ [11]. The US and China as two huge economies worldwide had reaffirmed the importance of strengthening bilateral cooperation in global climate change [12]. Furthermore, after COP 21 in 2015, they have been applying great efforts to bring Paris climate accord into force with more than 55 governments covering $55 \%$ of carbon emissions included to keep the warming tendency under agreed target of 2 C. China (20\%), the US (18\%), India (14\%) and EU (12\%) are collectively accounting for over $60 \%$ of global carbon emissions and China and the US pursue to limit global warming to $1.5 \mathrm{C}$ [13]. However, as the precondition, given the uncertainties existing in national carbon emission and international carbon leakage, it is important to establish an 
understandable, acceptable and rational scheme on precise quantification of carbon among countries to establish global carbon emissions mitigation in order to conduct international commitment on carbon reduction under the principle of common but differentiated responsibilities and respective capabilities [14].

with the new developments on carbon mitigation cooperation from rest of world, for example, the 2030 targets and ETS reform in EU, the cooperation in US and Canada on methane emission cut in oil and gas sectors by nearly $45 \%$ in 2025 comparing to 2012 levels, and the Green climate found projects [15], China has implemented many strategies to reduce her carbon emissions, for example, the US-China climate leaders summit in 2015 and a series of native targets in China's 11th-12th Five-Year Plan (2006-2015). Under great pressure in environmental cost especially carbon emissions from consumption of fossil fuel, China's 13th Five-Year Plan (2016-2020) announces 5 billion metric tons of coal equivalent energy consumption cap [16] and plans to reduce energy intensity and carbon intensity by 15 and 18 percent respectively, five-sixths of which will be achieved by improving energy efficiency and shifting the industry structure from heavy to less energy-intensive sectors and one-sixth by renewable and nuclear energy [17]. Although coal demand in China dropped for continuous second year in 2015 (64\%, comparatively reduced 3.7\% in 2014 and $10 \%$ in 2011) with the growth rate of economy slowing down which may leads to China exceed her carbon target in 2020 by $10 \%$ [18], to balance regional economic growth and energy consumption reduction in China, the carbon reduction strategies should response to regional unbalance on economic developments, for example, the vast gap on per capita carbon emission and carbon emission intensity between developed regions like east coast and undeveloped regions from the north west [19], the energy consumption structure and energy density, and regional industry distribution in China [20,21]. As one of the effective carbon mitigation schemes being implemented in EU and the USA, China's carbon emission trading market will expand from the current seven pilots to nation level by 2017, and will encompass six industrial sectors as planed during China's 13th Five-Year Plan [22]. The establishment of carbon trading market in China could monitor and control carbon emission effectively for specific regions and industries as an important supplementary of the carbon tax and subsidies in China [23]. In sum, the individual carbon emissions should be measured initially to distribute the carbon responsibilities among regions in 
China as well as China and her trade partners. Given the fluctuation of the estimates on carbon emission for China in the literature, it is therefore crucial to systematically review the methods, data and principles during calculating carbon emission from the literature to more reasonable carbon evaluation framework [24].

As the largest developing country and top energy user in the world [25] whose carbon emission equals to the total emission from the US and the EU during 1950-2012 [9], there is no doubt that China should be actively responsible for global climate change. However, to obtain more rational and effective climate policies for China or worldwide, some problems should be considered firstly --How much should China be charged for the global carbon emissions? How to define and measure the carbon responsibilities reasonably for one country? Should we suspect the current international principles calculating carbon emissions responsibility? How does the foreign demand contribute to China's carbon emissions? What makes China to be the top carbon emitter? Who should be responsible for $\mathrm{CO}_{2}$ emissions embodied in China's foreign trade? How to divide the carbon emission produced from China and her trade partners? As is known, the satisfied answer should be obtained from China and her trade partners rather than China per se because of the increasing global economy integration, fragmentation of production and global value chains (GVCs). To answer the questions mentioned above, publications have shown a dramatic boom on quantitatively investigating China's embodied carbon in trade especially the balance of the embodied emissions for China [26-32]. With different motivations, data processing and models designing, the existed empirical studies on ECCT are with large variability. To obtain consistent empirical results of China's embodied carbon emissions; it is necessary to make a survey on researches of ECCT, compare the quantitative results and trace the results uncertainties systematically.

The ECCT has been surveyed in previous review studies with different perspectives, such as setting China along with other countries together to investigate China's carbon emissions; and integrating carbon emissions with other China's environmental issues. Liu and Wang [33] analyzed the $\mathrm{CO}_{2}$ embodiment in international trade based on the quantitative literatures, and they confirmed an obvious imbalance of net $\mathrm{CO}_{2}$ embodiment in goods trade between major developed countries and emerging economies. China is a net carbon exporting country in 1997-2006. Sato [34] reviewed the quantitative results of embodied carbon in international trade for some countries (China, the 
USA, Japan, the UK, Denmark, Brazil, and India) to compare and discuss the methodological and data issues contributing to the variability of the results covering over 50 papers. The quantitative results of ECCT had been listed along with other countries in this survey with a worldwide perspective; it's therefore not a specialized study of ECCT. Nejat and Jomehzadeh [35] reviewed the researches of the status and current trends of energy consumption, $\mathrm{CO}_{2}$ emissions and energy policies in the residential sector, both globally and in 10 countries (China, the US, India, Russia, Japan, Germany, South Korea, Canada, Iran, and the UK). Hawkins and Ma [36] surveyed the studies of Chinese environmental issues using environmentally extended input-output analysis (EEIOA), the results show that the EE-IOA is used to study the issues like energy, $\mathrm{CO}_{2}$ and land use in China, and a large number of publications are on China's carbon emissions.

The bibliometric approach, as a powerful tool to explore, organize and analyze a large amount of information in a quantitative manner [37], has been widely applied to measure the development of a certain research field [38-41]. Zhang and Wang [42] evaluated the wetland research between 1991 and 2008 based on the Science Citation Index (SCI) published by the Institute of Scientific Information (ISI) using an effective bibliometric analysis. Fu and Ho [43] applied the bibliometric analysis to study the solid waste research to evaluate the current trends, using the literature in the SCI database from 1993 to 2008. Ferenhof and Vignochi [44] using bibliometrics studied the aspects of environmental management systems in small and medium enterprises incorporating their production processes based on scientific publications.

Recently, bibliometric analysis was used to review the research field of climate change, carbon emissions, EE-IOA and environmental topics for single country or worldwide. Wei and Mi [45] utilized the bibliometric method on climate policy modeling based on the online version of SCI-E from 1981 to 2013 and SSCI from 2002 to 2013 and summarized several hot research topics and methodologies in this field. Hawkins and Ma [36] applied the bibliometric analysis to survey the published articles regarding EE-IOA for China in peer-reviewed journals and provided a comprehensive overview of the body of literature. They examined the research impact, environmental issues addressed, and data utilized on the basis of online SCI-E and the SSCI. Mao and Liu [46] depicted existing research activities and future directions of alternative energy based on the SCI-E and the SSCI by bibliometrics. 
The main purposes of this study are firstly to survey the quantitative results of the ECCT from the existed empirical studies; secondly study the involved methodologies and the variation of the quantitative results, thirdly track the potential issues and strategies of the results uncertainties. We focus on the ECCT rather than all the China' environmental issues studied by EE-IOA comparing with the work of Hawkins and Ma [36]. Furthermore, vis-a-vis the research by Sato [34], we particularly review and compare the variation of the ECCT with respect to more updated literature and discrepancies (for example, the data collecting and processing, the regional economic imbalance on carbon emissions) in measuring ECCT. It should be noted that, as far as we know, such a single survey focusing on ECCT has not been summarized yet.

The rest of the article is structured as follows. Section 2 provides the methodologies in searching for the existed studies on the issue of ECCT in the SCI-E and SSCI database. Section 3 describes the latest research by bibliometric analysis including quantities statistics, journals statistics, authors' statistics, institutions statistics, article citations statistics, and disciplines statistics. Section 4 presents a summary of the involved methodologies, accounting principles, and data sources, the variability of the empirical results on ECCT obtained by keyword frequency analysis, and then the potential reasons and strategies for such uncertainties are discussed. Section 5 releases some concluding remarks on future further research point of this field.

\section{Methodology}

The data in this study are obtained from the online version of SCI-E from 1981 to 2015 and SSCI from 2002 to 2015 from Web of Science. The updated searching date is September 1st, 2016. Although China's year of opening to the world economy was in 1978, we set the beginning year in 1981 when China's input-output data were available [47, 48]. It is notable that only studies on embodied carbon in China's foreign trade from English peer-reviewed journals are collected. It should be noted that besides the literature from Chinese mainland, literature from Hong Kong after June 1997 and Macao after December 1999 are included in this study. Literature from Chinese Taiwan province are excluded.

Defining which articles should be included is important in this study. We firstly searched by keyword, title and abstract to lock the key journals, organizations and countries in this field, and 
secondly paid attention to the authors and references of the key papers with high citations. Following the method referred by Hoekstra [49], we obtained the articles by the descriptors of "embodied carbon", "China", "international trade or foreign trade", "policy or policies" and "Input-output analysis or models". The corrigenda, errata, announcements and books referring to economic impacts of environmental issues and environmental accounts structure and construction were excluded. Besides, papers discussing Chinese energy intensity or domestic carbon emissions were also excluded, and those calculating the global carbon flows and leakage referring to China were included.

To investigate the differences of the results, the frequency analysis of keyword was used to discover the keyword containing the empirical results (for example EEE and EEI) in the abstract, contexts and their references. Fig.1 shows the research framework of this study. We firstly obtained the results by frequencies of keywords for each year and key authors; secondly, we summarized the results by publishing year, methodologies, data used; ultimately, we detailedly discussed the variability of the empirical results, and reasons and strategies of the uncertainties to get more reasonable results for ECCT.

\section{Literature overview}

\subsection{General statistics}

According to the results, there are 317 articles referring to the issue of ECCT. Especially, a significant recent boom on ECCT was released from 2010 to 2015 in the literature (see Fig. 2). From the growth rate of the publications recently, we could find that embodied carbon between China and other economies all over the world has been the hot topic since China's becoming the top carbon emitter in 2007. While with the available of the input-output database from GTAP, OECD, WIOD as well as Chinese government, the way of measurement of carbon emissions and the controversies on international carbon responsibilities have been lasting for nearly a decade with no effective results. Studies on multi-dimensional analysis on ECCT, for example, the accuracy of energy intensity, the regional input-output data, the regional carbon intensity, the trade benefit and environmental cost comparison, have been published in top journals like nature $[21,50,51]$ and nature climate change $[20,52]$ recently, which implies the important role of confronting China's 
carbon emission to the world carbon mitigation.

Fig.3 illustrates the number of publications and the percentage of most productive countries in global level on ECCT. We could find that China was significantly the most productive country out of the top six countries. Different from the previous studies, we herein not only showed the worldwide timeline of papers (see Fig.2), but also illustrated the quantities and dramatic increase of papers from China being the dominant country in this research field all over the world (see Fig.3 and Fig.4). We can also knew that over 20\% publications from USA and England focused on China's embodied emissions in foreign trade. It could be concluded that the focus of the carbon responsibility allocation in the international climate change negotiation are mostly locked in the top emitter - China, and top carbon consumers - the USA, England and Japan. The research tendency from China shown in Fig.3 indicates that China per se has been gradually raising the financial supporting on carbon mitigation research field in the past decade.

The academic development of studying on ECCT in China are plotted in Fig.4 which could be divided into two stages. Stage 1 was from 1981 to 2009 in which the number of publications was few and stable, and the stage 2 was from 2010 to 2015 in which the number of academic publications increased with a high growing rate. The result shown in Fig.3 was lower than the result in Hawkins and Ma [36], because this study just obtained papers related to ECCT but Hawkins and Ma [36] collected the whole publications using the EE-IOA method to China. In addition, the number of publications covered in this study focusing on ECCT is more helpful to investigate the variability of numerical results for ECCT from literature than Sato [34] who compared the quantitative results of embodied carbon in trade with a worldwide perspective. Comparing with the results in Fig.2, it could be found that the international research cooperation in the past five years resulted in the growing tendency of publications of China and more and more oversea scholars showed their interests on the carbon emission and related climate change issues on China.

\subsection{Journals statistics}

According to the top 10 journals that have the most publications in the field of ECCT, four are from Netherlands, three are from the USA, and two are from the UK and only one from China (see Table.1). All the journals are originally on issue of environmental sciences, energy consumptions, 
emissions and environmental engineering. The top three journals (Energy Policy, Renewable \& Sustainable Energy Reviews and Journal of Cleaner Production), as the most productive journals, had published 26\% papers on the embodied carbon emissions from China from 1994 to 2015. From perspective of changes in impact factor of these journals, we found that most of the journals were with a positive growth rate except journals of Ecological Indicators and Ecological Modelling. The impact factor of Renewable \&Sustainable Energy Reviews was with the most highly growth rate in the past decade which indicates its increasing importance as top journal in this research field.

\subsection{Authors statistics}

The top 10 most productive authors in the field of ECCT are listed in Table 2. We could know that the productive authors are from China mostly, but the citation results (see Table 4) shows that the highly cited paper are from other countries. The results show that Chen GQ from Peking University has published 26 papers being the most productive author in this field with the highest H-index. Chen GQ and Chen ZM are in the same lab named State Key Laboratory for Turbulence and Complex System in the Peking University. According to the results, top academic centers in China are sponsored by research foundations from Chinese governments (see Table 3). We also can see that the embodied carbon emissions in China have been studied by scholars from Singapore and England in Table 2, which indicates that the increasing attention to China's carbon emission in international trade and its role of mitigating carbon content during economic activities has been treated as an important global issue recently.

\subsection{Institutions statistics}

According to our results, there are nearly 100 different institutions showing research interest in this field around the world. University of Chinese Academy of Sciences is the top institution with a number of 46 productions (see Table.3). Besides, academic centers from China have taken up over half of the research centers and 60\% publications out of the total publications on ECCT. It indicates that institutions from China have the exclusive research position among all the involved think tanks in the world. Considering the hot debate on how to curb climate change as a political and economic problems globally as well as China's status of world factory in the past two decades, it could be 
deduced that China's role in cleaner production and environmental protection become more important recently. Therefore, more institutions from top academic organizations have studied issues on China's carbon emission. As shown in Table 3, Institutions from the UK (University of Leeds, University of London and University of Cambridge) published 20 papers, and there are 16 papers from National University of Singapore and Harvard University.

\subsection{Article citation statistics}

The top ten most cited articles in the body of literature along with the journals involved and the time of the citations and countries addressed are shown in Table $4^{1}$. We summarized the important papers in this field with over 200 time's citation in this table. The most highly cited article was from Peters and Hertwich [3] and published in Environmental Science \& Technology with 824 citations. Followed by article co-authored by Davis and Caleira [27] from the Department of Global Ecology in Stanford University and published in Proceedings of the National Academy of Science of the United States of America which was cited 719 times. The earliest work in this field by Wyckoff and

${ }^{1}$ The processing of self citation during bibliometric analysis are debatable and divergent up to now. The problem of self citation during processing the citation data for scholars could not be avoided completely in this study to keep the intact sense of the bibliometrics. Necessary (not intentional) self citation could be acceptable in bibliometric analysis. As explained by Aksnes [60] and Wolfgang et al., [61], reasonable self citation in the literature is rational and with little influence in measuring the citation times. The articles with high citations in this table are purposed to distinguish papers with high citations against other papers in this field, in other words, it is not to rank the citation of the publications but to just show publications with higher level here [62]. It is not appropriate to omit all the self citation case in special circumstance in bibliometrics. Moreover, a reasonable self citations are understandable and acceptable. To increase the implication and status in a specific research field, researchers in the same group or laboratory sharing a systematic research topics, usually cite theirs previous published papers to make some new contributions in their research field [63]. 
Roop (1994) published in Energy policy had been cited nearly 400 times. Three studies from China had been cited over 200 times which represented that studies from China has regularly performed theirs important role in this field worldwide. In addition, the boom of the literature citation from the results released that with China's being the top carbon emitter in the world [53] and the most important contributor to global climate change [54], embodied carbon from China has become a popular topic in the past decade [28, 30, 53-59].

\subsection{Disciplines statistics}

The study of ECCT is an interdisciplinary subject. From the SCI-E and SSCI database, over thirty subject categories are related to this topic. They can be divided into Environmental sociology ecology, Energy fuels, Business economics, Engineering, Science technology other topics, Geology and others. Publications from discipline of environmental sociology ecology, such as [28, 64, 67], account for $51.89 \%$ of the all publications (see Table.5). From the top disciplines, we could conclude that the phenomenon of inter-discipline are existed in this research field, for example, papers from the top journals are produced with Economy, Environment, Physics, Meteorology and Mathematics background recently. Moreover, the further detailed research could be launched than before since the development of the computing technologies, the cooperation established among disciplines makes the possibilities of deep investigation and research in integrated model on ECCT presently.

\section{Discussion}

\subsection{The involved methodologies}

From the literature, the input-output analysis [68-70] introduced in 1930s and latterly extended to EE-IOA [71, 72], is dominant analysis method to analyze the environmental issues especially energy-related carbon emissions in China. As a systematical environmental analysis model, EE-IOA is popular to measure the ECCT in the past decade. By the results of the keyword frequency analysis, we found that the single region input-output (SRIO) model, bilateral trade input-output (BTIO) model, and multi-region input-output (MRIO) model are the top three models applied to enumerate China's embodied carbon in trade. Besides, the computable general equilibrium (CGE), the physical 
IO [73, 74], the life cycle analysis (LCA) [75-77], and the hybrid MRIO-LCA [78-80] are also applied widely.

These methodologies, being complementary to some extent, provide different angles on the quantification of ECCT. Fig.5 plots the strengths and caveats of the major strands of research methods that map and measure the embodied carbon in Chinese foreign trade. Firstly, the x-axis indicates the complexity of data sources demanded to carry out the assessment; secondly, the y-axis refers to the accuracy of the resulting quantification, in other words, to what extent the precision of such measure of embodied carbons aiming to assess; thirdly, the size of the circle represents the coverage of the assessment which means to what extent the content of the measure encompasses the dimension of the research field. Each dimension is from 0 to 1 , higher values mean more complex data, and a more accurate final measure respectively. It is important to note that there are also many papers combining EE-IOA with the SDA [81-83], or IDA [84-86] to investigate the driving forces of the embodied carbon in international trade has been published.

The difference among the SRIO, BTIO and MRIO method on enumerating $\mathrm{CO}_{2}$ emission is summarized in Table 6 and the timeline of the main researches on ECCT by using SRIO, BTIO and MRIO model are illustrated in Fig.7. The SRIO analysis, assuming that imported goods and services are being produced with the same technology as the domestic products, is usually employed to measure embodied emissions connected to the total consumption for one country or region with the rest of world. Lin and Polenske [47] firstly explained China's energy use changes between 1981 and 1987 by using SRIO model and SDA in 1995. They argued that energy saving during research periods originally came from changes in production technology rather than changes in final demand shifts in China and the energy intensity decline since the energy efficiency improvements. Peters and Weber [63] analyzed how China's carbon emissions changed with her technologies, economic structure, and lifestyles by using the SRIO and SDA method. They found that China's productionrelated $\mathrm{CO}_{2}$ emissions increased by 59\% from 2,163 million metric tons (MMT) to 3,440 MMT from 1992 to 2002, and the net trade had a small but significant effect on China's total emissions since equal growths in emissions from the production of exports and emissions avoided by imports. The efficiency improvements offset consumption growth partially and improving both production and consumption systems can reduce emissions potentially. 
The BTIO model, considering the variability of $\mathrm{CO}_{2}$ emission factor from different countries and decomposing international trade by trading partners, is mainly used to enumerate the carbon emissions induced by consumption abroad between trade partners for single country or region. Comparing to SRIO method, BTIO can get more accurate results by relaxing the import substitution assumption. Shui and Harriss [30] estimated the $\mathrm{CO}_{2}$ embodiment in US-China trade during 19972000. By using data from the US Census Bureau, the $\mathrm{CO}_{2}$ emission factor for US exports to China from the economic IO-LCA software developed by Green Design Initiative at Carnegie Mellon University, and the corrected $\mathrm{CO}_{2}$ emission factor for Chinese exports to the US, they found that the $\mathrm{CO}_{2}$ emission increase by $3 \%$ if the imported goods from China produced in the US and up to $14 \%$ $\mathrm{CO}_{2}$ emitted by China for exporting to the US. In light of Shui and Harriss [30], the embodied emissions in China-UK trade was examined by Li and Hewitt [66], they released that the UK avoided $69 \mathrm{MT} \mathrm{CO}_{2}$ emission since importing goods from China in 2004, and it means $186 \mathrm{MT} \mathrm{CO}_{2}$ emission in China due to great carbon intensity of Chinese industry. The UK had exported 2.3 MT $\mathrm{CO}_{2}$ to China in the same year. Besides, the sea transport of goods between the UK and China resulted in $10 \mathrm{Mt}$ of $\mathrm{CO}_{2}$ reducing globally in 2004. Su and Ang [87] employed the BTIO (EEBT) model and hybrid emissions embodied in trade (HEET) approach to examine the impact of the spatial aggregation on the estimates of the ECCT.

The MRIO model, distinguishing the direction of imported goods from the intermediate inputs and final consumption endogenously, can perfectly capture the re-exported products and the feedback effects to track complete carbon footprint at national and supranational level [61]. From the keyword frequency analysis, a large number of papers applied the MRIO model to study ECCT especially in the latest decade. Liang and Fan [100] established a MRIO model for Chinese energy use and $\mathrm{CO}_{2}$ emission by dividing China into eight regions. Their results revealed that population growth significantly affected both of the energy requirements in and out of the regions itself. They found relative errors between emissions caused and emitted by a region is significant, and hence different identification of responsibility would result in different impacts in China's environmental policy reform. Weber et al. (2008) evaluated China's contribution to global climate change. They argued that $33 \%(1,700 \mathrm{Mt})$ of China's domestic $\mathrm{CO}_{2}$ emissions in 2005 were exported which increased from 12\% (230 Mt) in 1987 steadily. The growth rate of China's total emissions was lower 
than that of the exported emissions in 2002-2005. Davis and Caldeira [27] examined the global carbon flows based on GTAP-7 and released that $23 \%(6.2 \mathrm{GT})$ of global $\mathrm{CO}_{2}$ emissions primarily from China exported to developed countries in 2004. Su and Ang [101] analyzed the feedback effects by using a MRIO model and the data of Asian international input-output table 2000 [102] They noted that the results of MRIO were lower than those of BTIO. In addition, China emitted 2,655.8 Mt $\mathrm{CO}_{2}$ emissions under the MRIO, but 2,670.1 $\mathrm{Mt} \mathrm{CO}_{2}$ emissions based on the consumption-based principles by considering the feedback effects. With sector classification more detailed and better coverage of world economies, such estimation for carbon emissions can be more effective and accurate. Besides, the effects of spatial aggregation and the difference of processing and normal exports under MRIO on ECCT were discussed by [87] and [31].

The other methods estimating embodied emissions plotted in Fig.5 are showing a growing boom in the literature. Especially the MRIO-LCA (hybrid) and LCA are bottom-up process-based method considering the sector disaggregation to depict the sector level emissions [30]. The CGE model can be used to measure and simulate the volume of the embodied emission from changes in socioeconomic structure [103]. The physical IO model only use the physical quantity data relatively [104].

\subsection{The involved accounting principles}

To better understand the responsibility of GHGs emissions between consumers and producers, a definite and rational principle of measuring the carbon responsibility should reach an agreement globally. From the results of the literature review, the popular principles involved in measuring the carbon emissions are the production-based (or territorial) accounting principle and the consumptionbased (or upstream) accounting principle in the literature. In addition, the common but differentiated responsibility [105], the shared producer and consumer responsibility [106], and the income-based principles [107] are also discussed.

The production-based accounting principle implemented by United Nations Framework Convention on Climate Change (UNFCCC) and Kyoto Protocol is the dominant framework on measuring the industrial GHGs emission responsibilities of countries. Because of the disapproval from the non Annex-1 and some Annex-1 countries with respect to production-based accounting 
principle (see Fig.6), the progress of the international climate change negotiations is less effective in carbon mitigation. Alternatively, the consumption-based accounting principle had been argued strongly, based on the carbon footprint and carbon leakage in trade, as a substitution.

Recently, studies juxtapose both of the consumption and production based emissions to demonstrate the impact of trade on the national emission inventory. As Fig.7 illustrates, we can learn that $\mathrm{CO}_{2}$ emissions are significantly different in China from the Production-based and Consumptionbased principles in 2009. With the increasing volume of international trade in countries like China, a more reasonable accounting principle is urgently in need. However, justice and fairness on allocating carbon responsibility are complex and targeted on global scale.

\subsection{The involved data sources}

The IO table and carbon emission data-gathering problems in China have thus far been acutely focused globally. It can't be denied that the data sources and processing would lead to the variation of the results. Wang [50] argued that China had the capacity to abate carbon emissions if she can deal with the problem in data gathering and implementing reliable system for gathering carbon data as soon as possible. With the efforts implemented from the Chinese government and institutes abroad, the Chinese IO table has become more available with higher quality.

The main available input-output database used in ECCT from the literature are summarized in Table 7. The input-output tables, energy data, $\mathrm{CO}_{2}$ emission data, trade data and other economic data applied in calculating ECCT can be obtained from various sources. With different data processes, it may lead to the results variation. The uncertainties resulted from data sources and processing, the impact of the regional economic imbalance on Chinese IO tables will be discussed in section 4.5.

On the other hand, the energy data can be obtained from the China statistical yearbook and GTAP database. The carbon intensity data can be obtained from International Energy Agency (IEA) and World Resources Institute (WRI). The $\mathrm{CO}_{2}$ emissions are usually calculated based on the IPCC guidelines in 2006 and Chinese energy statistics. For ease of explanation, some authors just use the $\mathrm{CO}_{2}$ emissions data from their own or other previous literature. In addition, the national carbon emission data can be obtained original from the World Input-Output Database (WIOD) database. It should be noted that some studies just use the data and coefficients from other countries to represent 
Chinese data, more details are surveyed in [36].

\subsection{The quantitative results of ECCT from literature}

Based on the results of the keyword frequency analysis, we track the empirical results of ECCT from the key papers (and their references), authors, organizations, and then try to summarize the empirical results for ECCT one by one. In the light of the analysis process in previous studies [34, 36, 49], the aggregate results are summarized in Appendix A. From the literature, under different research motivations, uncertainties in PBE, CBE, EEE, EEI and EEB can be investigated from the methodologies, data processing and assumptions from the authors. The ECCT in literature are so volatile in the same year with same calculating principles under different data sources and processing. Meanwhile, even with same assumption on the carbon emissions coefficient, the different estimate of ECCT can be found, such as [125] and [126] with different sources of IO data in the same year.

\subsubsection{The fluctuation of the PBE and CBE}

From the set of literature covered in this study, the earliest estimate of China's PBE and CBE are 1,569.2 $\mathrm{Mt} \mathrm{CO}_{2}$ emissions and 1,426.9 $\mathrm{Mt} \mathrm{CO}_{2}$ emissions in 1985 estimated by Shimoda and Watanabe [112] by using a MRIO model and data from the Asian international input-output table from IDE (see Table.7). They released that the net export $\mathrm{CO}_{2}$ emission from China was positively, and indicated that China was a net carbon exporting country in 1985. In fact, Liu [9] estimated China's $\mathrm{CO}_{2}$ emissions from 1970-2012, we could obtain the earliest PBE nearly 0.7 Gt in 1970 in this report. He applied his own estimated China's energy data based on mine-level and factory-level energy use data to calculate China's carbon emission, and finally argued that methodologies and verifications in full transparency towards better energy and emission data for China are urgent needed.

The estimate of yearly PBE and CBE suffered a drastic fluctuation. As shown in Fig.8, the PBE is varying from over 2,700 $\mathrm{Mt} \mathrm{CO}_{2}$ emissions [127] to over 3,000 $\mathrm{Mt} \mathrm{CO}_{2}$ emissions [60] in 1995 with the change rate of over $9 \%$. In addition, the small variation of estimate on PBE in 1997, 2000, 2001, 2003, 2004 and 2005 can be learned from Appendix A. Contrarily, the PBE in 2002 is between 
2,600 Mt $\mathrm{CO}_{2}$ emissions [109] and 3,600 $\mathrm{Mt} \mathrm{CO}_{2}$ emissions [60] with the change rate of around $39 \%$, such large variation also can be found in 2007. Weitzel and Ma [128] applied the MRIO method to measure the PBE in 2007 and they came to nearly 4,000 $\mathrm{Mt} \mathrm{CO}_{2}$ emissions, comparing to the estimate from Yan and Yang [65] by using a SRIO model, they are lower than over 50\%.

Besides, the fluctuation tendencies of yearly PBE are rising regularly. The PBE is around 3,000 $\mathrm{Mt} \mathrm{CO}_{2}$ emissions in 1995 and 2000. Continuously, the values of PBE are up to over 3,000 $\mathrm{Mt} \mathrm{CO}_{2}$ emissions in 2002 and 5,000 Mt CO 2 emissions in 2007. To some extent, we can see the effects of the Asian financial crisis in later 1990s, and the entering into the WTO in earlier 2000s to China's economy, in particular, the increasing of the energy consumption and the acute global academic attention (see Fig.2) to Chinese economy growth and resulted carbon emissions in the past decade.

On the other hand, we can learn that the $\mathrm{CBE}$ is varying from $2,152 \mathrm{Mt} \mathrm{CO}_{2}$ emissions [127] to over $3000 \mathrm{Mt} \mathrm{CO}_{2}$ emissions [129] in 1995 with the change rate of over 20\% from Fig. 8. Moreover, the $\mathrm{CBE}$ in 2002 is varying from $1,841 \mathrm{Mt} \mathrm{CO}_{2}$ emissions [109] to $4030 \mathrm{Mt} \mathrm{CO}_{2}$ emissions [60] with a great variation rate of over 54\%. Comparing with the existed studies, Xia and Fan [109] used a non-competitive DPNHIO (extended IO models, more details see [130]) model to measure the ECCT in Chinese processing and non-processing exports sectors with new assumptions of estimating the emission intensity in China, and disaggregated the energy sectors into three parts like domestic use of energy, processing exports and non-processing exports. The estimate of CBE in 2004 demonstrates a dramatic variation with the change rate of $35 \%$ implying more uncertainties in data processing from the literature (see Appendix. A). As expected, wider fluctuation can be found in 2005 (from 3,370 $\mathrm{Mt} \mathrm{CO}_{2}$ emissions to 5,400 $\mathrm{Mt} \mathrm{CO}_{2}$ emissions). To understand the performance of the discrepancies in ECCT, it is valuable to discuss the variations emerging from the methodologies data and assumptions in greater details. It seems that the estimates of CBE in 2000 (from 2,305 Mt CO2 emissions to 2,794 Mt CO2 emissions) are with little inconsistencies. Commonly, a higher PBE than CBE could be resulted from the economy with same trade structure from overseas like China because of the difference of the production-based and consumption-based principle on assessing $\mathrm{CO}_{2}$ emission.

It is meaningful to discuss that the gap between PBE and CBE became larger more or less from 1995 to 2005 in Fig. 8. In other words, different from the gap between PBE and CBE from 2000 to 
2002, both increasing in PBE and CBE from 2002 to 2005 reveal an increasing volume of EEB of China. We should firstly note the energy consumption rather than the economic growth, to some extent, whilst the low energy efficiency by PBE. Secondly, the increasingly development of Chinese international trade and the abroad intensified demand of the high carbon embodied goods especially in 2005 may contribute to such gap. For example China had exported net $656.68 \mathrm{Mt} \mathrm{CO}_{2}$ emissions to the US which took up $11.67 \%$ and $13.9 \%$ of the total $\mathrm{CO}_{2}$ emissions in China [131] and the US [132] respectively in 2005 .

\subsubsection{The fluctuation of the EEE and EEI}

The EEE and EEI of ECCT had been estimated from 1987 to 2011 (see Appendix. A), which show a big volatility significantly. For example, on the one hand, the EEE in 2000 is from $350 \mathrm{Mt}$ [65] to $1,000 \mathrm{Mt} \mathrm{CO}_{2}$ emissions [126], and the same or even more bigger difference can be found in 2002, 2003, and 2004; On the other hand, the EEE in 2001 is from 2,849 $\mathrm{Mt} \mathrm{CO}_{2}$ emissions [65] to 2,930 $\mathrm{Mt} \mathrm{CO}_{2}$ emissions [29], and the small variation can be learned in 1997 and 1998. However, the EEI of ECCT in 1997 is varying from $102 \mathrm{Mt} \mathrm{CO}_{2}$ emissions [26] to $700 \mathrm{Mt} \mathrm{CO}_{2}$ emissions [60]. The big fluctuation in EEI can also be found in the rest years.

The EEE of ECCT in 2005 is changing from $422 \mathrm{Mt} \mathrm{CO}_{2}$ emissions to 3,357 $\mathrm{Mt} \mathrm{CO}_{2}$ emissions, and the EEI is varying from $120 \mathrm{Mt} \mathrm{CO}$ emissions to $2,333 \mathrm{Mt} \mathrm{CO}_{2}$ emissions. Given the carbon intensity in China is higher than most other countries/trade partners, does China always have the higher EEE than EEI? The answer is no. Different from other results, Weber and Peters [60] got the higher EEI than EEE in 2005, using the SRIO model and the IO table from NBS-PRC (see Table7). They found China clearly avoided large $\mathrm{CO}_{2}$ emissions from 1987 to 2005 . To explain the abnormal estimate, they noted that the EEI in 2001 should be estimated to be $216 \mathrm{Mt} \mathrm{CO}_{2}$ emissions when they illustrated the EEI up to $1,170 \mathrm{Mt} \mathrm{CO}_{2}$ emissions in 2002.

The changes of the EEE and EEI are significantly different under different models in the same year. The most waving characteristics for EEE and EEI can be found specifically by detailedly checking the EEE and EEI from the reported results in Appendix. A. As shown in Fig.9 for 2005, the variability of the EEE and EEI from the MRIO are smaller than SRIO. The average fluctuation of the EEE and EEI based on BTIO are smaller than those of based on SRIO. In the results of the 
each model, the variations also exist in the same year. For example, in terms of the EEE and EEI in SRIO, we can see that the values of EEE and EEI from [28] are larger than others which means that the carbon embodied in China's exports are more than that of imports with the increasingly demand abroad of the energy intensive goods produced by the high carbon embodied intermediate goods imported or domestically. Contrarily, the EEE and EEI from [133] are with little gap compared with the other results applying the SRIO model. They identified the volume of domestic and imported goods in the inter-sector input and final use in IO table by data from China Customs Statistical Yearbook released officially in China.

Lin and Sun [28] measured the EEE and EEI of ECCT by SRIO and BTIO in 2005 respectively. They argued that the EEE and EEI should be calculated by using the emission factors of the exporting and importing countries to avoid overestimate the imported and re-exported emissions in China, since Chinese producing process is more carbon intensive than her trade partners. As shown in Fig.9, we can see the obvious difference in the results of EEE and EEI in 2005 between the two methodologies. In addition, Zhao and Zhang [114], by considering the impact of global vertical specialization on ECCT and using the IO tables from the WIOD (set 1995 as base year), measured ECCT by differentiating the domestic sourced $\mathrm{CO}_{2}$ emissions from the foreign sourced emissions and the re-exported emissions embodied in international trade. Their results of EEE and EEI covered the average results by the MRIO model in 2005 (see Fig.9).

\subsubsection{The fluctuation of the EEB}

Based on equation EEB=PBE-CBE=EEE-EEI and the results from the literature, the EEB are calculated in Appendix. A. As mentioned in section 4.4.1 and 4.4.2, we can get some clue about the variation of the EEB for ECCT indirectly. Fig.10 and Fig.11 show the variation of EEE, EEI and EEB in 2002 and 2007 respectively. From the tendency of the EEB, the great variation within every year cannot be ignored. For example, The EEE in 2007 changed from $478 \mathrm{Mt} \mathrm{CO}_{2}$ emissions to over 3,000 $\mathrm{Mt} \mathrm{CO}_{2}$ emissions, the EEI varied from $140 \mathrm{Mt} \mathrm{CO}_{2}$ emissions to over $1,782 \mathrm{Mt} \mathrm{CO}_{2}$ emissions, and the EEB is range between $102 \mathrm{Mt} \mathrm{CO}_{2}$ emissions and over 2,900 $\mathrm{Mt} \mathrm{CO}_{2}$ emissions (see Fig.11). The parallel circumstance also can be checked in 2002 (see Fig.10), 2004, and 2006. It seems the estimate fluctuation in 2007 is smaller than 2002. 
The largest EEB in 2002 and 2007 are estimated by [126], they obtained the IO table data from the OECD database and replaced the IO table in 2001-2004 with 2000, 2006-2010 with 2005. Based on the emissions avoided by imported (EAI) assumptions, they got adjusted technical factor for China's import by assuming China only trade a single "virtual country". From the EEI plotted in Fig.10 and Fig.11, with higher EEE, we can conclude a higher EEB for China consequently. In addition, the smallest EEB in 2002 and 2007 are obtained by Zhang [133], as mentioned 4.4.2, followed by Weber and Peters [60], they avoided double counting on the goods and services in the bonded areas by customs data in IO table.

The estimate of EEB is affected by the assumption about the importing country pe se and its trade partners. In addition, Xia, Fan [109] applied South Korea's technical coefficients as those of China's trade partners to study ECCT, they certified if technical coefficients of South Korea are employed to measure the carbon avoided via import, China is found to be a net importer of embodied carbon in 2001-2005, and a net exporter from 2006-2009, then turned to be a net importer in 2010. However, the technical coefficients from South Korea would underestimate the EEI, then if the EEE is consistent, the EEB of ECCT would higher and China would be a net carbon exporter. From the literature, although EEB in 2005 fluctuated actively (see Figure. 11), it could be concluded that most of the estimates are located between $500 \mathrm{Mt}$ and $1500 \mathrm{Mt}$. By checking the technical coefficients used in those papers, comparing to SRIO and BTIO, the MRIO is the most precise model to estimate variation of production level among trade partners. Literature considering the differentiation in economic technique and energy intensity between China and her trade partners could get the more accurate net carbon emission embodied in international trade.

With the development of international trade, the fragmentation of the production and consumption worldwide has attracted more and more attentions. As plotted in Fig.10, the similar EEE may lead to a totally different EEB with the different consideration on EEI, which indicates that the assumption of the imported goods should greatly change the EEB finally. Wiedmann [61] reviewed the MRIO model used for consumption-based emission, he argued the adjustment of imported goods consumed in domestic inter-sector input and finial consumption can bias the estimation to a large extent. The carbon emission embodied in the re-exported goods produced by the imported intermediate input should be divided from the domestic inputs. Therefore, he concluded the 
accuracy of MRIO and more complex extended IO models should be deduced to handle the uncertainties in estimating embedded carbon in trade.

\subsection{Reasons and countermeasures to the results uncertainty}

Considering the differences existed in the estimate of the ECCT as summarized in section 4.4, it is impossible to plot a general trend or level for the change of ECCT. As a result, it should be borne in mind that finding the potential reasons for such uncertainty and reducing the variation in estimating ECCT is meaningful to policy implications.

\subsubsection{The methodology specification}

The MRIO has been the most popular method to measure the carbon emissions embodied in China's foreign trade. With wider availability of the increasing capacity on computing technology and economic accounts, environmental accounts and foreign trade data, many recent literature juxtapose carbon emission by MRIO model. The complex feedback and spillover effects between trade partners can be perfectly plotted by combining the domestic technical coefficient matrices with the import matrices from multiple countries or regions into one large coefficient matrix in the MRIO model. In fact, it is worth to note that the MRIO and its extended forms can be various with different modeling background and available data lags $[61,104,134,135]$. However, with the differentiated technologies from multiple countries being considered, the international IO databases, such as the WIOD, GTAP, EORA, and GRAM [136] have been developed to catch the carbon emission flows in terms of country, region, municipal, sector, and product. China's carbon footprint has been estimated from the macro to micro scale as shown in the literature [137]. Based on extended MRIO model, it is meaningful to track the carbon flows globally from cradle to grave. The structural path analysis (SPA) [138], the structural path decomposition (SPD) [139], the RAS structural decomposition approach [140, 141], the MRIO-LCA [142, 143], GTAP-MRIO [136, 137, 144] and carbon emissions measurement integrating with the GVCs can be used for investigating the environmental impact of ECCT from the international supply chains [145].

However, there exist inherent uncertainties in MRIO [61] which only be discussed recently. Firstly, the assumption of the production technology of trade (import) goods are identical to the 
importing country which could cause unbalanced allocation on technology differentiation among trade partners; secondly, data located on the off diagonal matrix in MRIO table related to trade relationships between trade partners only can stand the supplying sectors from specific country to the other, but have no clues on how to distribute those import goods or service in imported countries by sectoral level, therefore, the imputation techniques with inherent assumption usually being applied to produce the trade flow matrix of the off diagonal matrix as a replace; thirdly, the level of sector aggregation or disaggregation could impact the estimate. Lenzen and Pade [146] tested the variation caused by the sector aggregation from 10 to 133 sectors, they concluded that the merge of the electricity production to water and gas production could significantly resulted in the variation in estimate, moreover, Su and Ang [32] concluded that around 40 sectors could obtain the stable and reasonable estimate for an economy by testing the effect of the sector aggregation.

Comparing with the MRIO model, the SRIO and BTIO model have their own merits as well as shortcomings in measuring the carbon emission in the earlier literature. The SRIO could be used to measure the carbon emission for a unique country with the merit of low requirement of data source to input-output table and trade data under competitive circumstance. However, the import substitution assumption [29, 147] and the emission avoided by importer assumption [28] under SRIO approaches with lower requirement on data would definitely lead to biases in carbon emission embodied in imports. From the literature, it is inadvisable to adjust the carbon coefficient from other countries for China's imports [30, 65]. For a large country like China, the production technologies are with high extent of variation among regions since the economic imbalanced background, the characteristics of carbon factor and production technologies, if possible, should be better considered provincially or regionally to study the location of the carbon emissions clearly and obtain more accurate results of ECCT.

Comparing with the SRIO model, the BTIO method divides the domestic and imported good and service as the improvement. However, with the failure of dividing the imported intermediate input and the final demand from the import goods, the BTIO (EEBT) would mix the sectoral carbon emissions embodied in some imports goods by sector aggregation. In spite of the relaxing assumption on carbon factors, only considering carbon emissions between main trade partners in BTIO model cannot draw the detailed carbon flow during international trade [104, 148]. Therefore, 
the sector disaggregation should be a more accurate way to estimate embodied carbon in the further study. Besides, it is the energy intensity in China that cannot be assumed as a whole roughly. For example, with the large amount of exports and imports in China's eastern coastal regions and theirs economic hinterland, the processing trade with low profits and high carbon responsibilities should be reasonably measured. The carbon emission sourced within and without China therefore should be clarified. Therefore, more detailed multi-regional input-output table, energy use account and robust emission evaluation method should be developed for each of the economies at global scale respectively [9].

\subsubsection{The accounting principle specification}

Shall we turn to consumption-based accounting principle now? As discussed in section 4.2. We can conclude that the better way to get progress in the international climate change negotiation is ending the current unreasonable production-based accounting principle [134] as soon as possible for more effective carbon abatement progress. For instance, large developing counties like China and India would show more confidence on the GHG reduction if the carbon responsibility can be divided more fair and reasonable between the real carbon consumer and producer.

China would be an obviously net carbon exporter if the re-exported goods produced by high imported intermediate goods and embodied with low Chinese domestic carbon commonly being considered to be Chinese carbon responsibility [143]. The wider discussion on the consumption based accounting principle can be found in [27, 106, 142]. As a better choice of carbon responsibility, the common but differentiated responsibility, uncovering the indirect carbon emission for government and even clearly showing the sources of GHG emission for the consumers, is perfect but with great obstruction coming into force. However, international cooperation, such as the cleaner technology transfer and streamlining the clean development mechanism should be considered to implement between developed and developing countries.

\subsubsection{The data source specification}

The data source uncertainties mainly lie in the reliability of the underlying statistics for the IO table, the normalization for emission data [140], and the impact of sector aggregation or spatial 
disaggregation. Besides, the price adjustment and the disposition of the trade data with different policy consideration on methodology design can vary the EEB of the ECCT by biased estimate on PBE, CBE, EEE, and EEI. To obtain more accurate estimate for ECCT, these uncertainties should be under control during the initial statistics rather than being overlooked.

Firstly, the IO table and emission data in China should be with high quality. The biases existed from the processes of gathering supply-use tables (SUT), input-output tables (IOT), international trade data and emission data should be controlled in China. The number of the commodities, sectors and the methods of reconciling the various datasets must be uniformed initially [149]. Although Chinese government has implemented measurements to data collection, the questioned and disputed voice never stop $[63,73,74,145,150]$. The SUT is the basic database for the industry by industry IOT, to avoid the uncertainties during this process, the SUT is directly employed in MRIO model recently which however increase the uncertainties simultaneously. The IOT, for ease of explain, are usually aggregated in fewer sectors which would contribute a fuzzy result of the consumption coefficient. The trade data should carefully match the IO table in trade partners. In particular, under BITO or MRIO model, the trade data should be allocated reasonably. It would be difficult but helpful that the emission data in China should be gathered in sector level to describe more issues of carbon emission embodied in Chinese export. Meanwhile, due to the different regional industrial structures in China, the emission data should be collected regionally to track and abate the carbon emission at region/sector level in China purposely [151].

Secondly, Chinese IO table and energy intensity data should be more detailed, standard and wellgathered. From the literature, the popular databases used in analyzing the ECCT are from the NBSPRC, the IDE-JETRO, GTAP, OECD, WIOD, EORA and EXIOBASE. The Chinese national IO table, regional IO table, provincial IO table and the large municipal IO table collected originally or updated by special technique (such as the RAS method $[134,140,152])$ are available online now. In addition, the Asian IO tables produced by IDE-JETRO and the ICIO database released by OECD database are also widely used for ECCT recently. Since the database of GHGs and sector coverage in IO table are organized systematical different, the aggregation is unavoidable. Studies should pay attention to the errors resulted from the sector aggregation when the number of sectors from the IO database does not match that from the energy sectors. Existed studies show that the highly 
aggregated sectors would result in a higher estimate of carbon emission than the results with sector disaggregation process. It should be noted that more assumptions and uncertainties would emerge in sector disaggregation as trade off. More detailed discussions about the degree of aggregation in the IO tables can be learned from $[108,153]$.

Thirdly, the large scale computer systems should be developed for large scale of data involved which would beyond the calculation capacity of the personal hardware resources. To capture the real carbon flows for China worldwide, the data from multi-country should be gathered within an international criterion [121]. Therefore, the MRIO should make full use of the large scale computer system to try to demonstrate the main features of the carbon emission flows [134, 144]. Current understanding of the natural and social sciences of GHGs is still need to be improved with the development of the data gathering approach and the methodology extended. Although the GTAP-E model, the EORA model, the GRAM model and the CGE model have been build up to deal with such issue, the processes seem like a black box. As a summary, it is important to build up a national calculation system currently including all the elements, such as the Chinese regional carbon emission database, the producing process, the trade and transportation process, the feedback and spatial mechanisms, to capture the carbon emissions. Most of the existed studies are relative static and policy oriented $[35,143]$. To limit the uncertainties during environmental impact evaluation, it is important to develop an integrated MRIO model with large scale computer system for China to describe the embedded emissions globally.

\section{Concluding remarks}

The mitigation of the domestic carbon emissions and ECCT are not only an economic issue but also a political game for China. Ambitious commitments and efforts have thus far been made to control carbon emissions by Chinese government. Although the uncertainties of numerical investigation of ECCT are large and varying, the estimates remain reasonable and practical in providing insights and policy implications on Chinese carbon reduction in international trade. In particular, most of the articles on ECCT published by authors from China are financially sponsored by Chinese government. With the international climate change negotiation reaching more effective global agreement [154], as the largest developing country and top carbon emitter, China should 
handle her carbon emission and keep a good balance between the economic growth and environmental protection [155].

The increasing number of the studies on ECCT makes it possible to compare the methodologies, data sources, and estimated results of the ECCT critically. To assess the existing level of numerical understanding of the ECCT, this study provides a comparative review of the quantitative estimates on ECCT by surveying the empirical results from the literature based on the online version of SCIE from 1981 to 2015 and SSCI from 2002 to 2015. It should be noted that only the English language peer-reviewed journal articles are surveyed, consequently, the conclusions drawn herewith for ECCT cannot be extended to Chinese or other non-English-language literature. In the discussion, we learn that studies on ECCT are robust in the past decade, and the series of IOA approaches are dominant methodologies used to analyze ECCT, and the obvious inconsistencies and uncertainties can be found by comparing reported results taken from the literature.

The MRIO model and its extensions have been the dominant method to measure the environmental issues all over the world especially for China. With the increasing improvements on China's energy intensity and carbon emission intensity data, and more detailed IO tables (such as the expansion of regional and municipal IO tables), the boom of the EE-IOA studying on $\mathrm{CO}_{2}$ emissions embodied in international trade for large carbon consumer and producer (such as the EU, USA, China, and India) would be more prosperous in next decade for the white-hot debate on carbon responsibility distribution in global climate change negotiation. As discussed by Dietzenbacher and Lenzen [156], the MRIO model will be used to draw the connection between the economic and the environmental issues closely with the building of the giant database including detailed data worldwide. As a hub for global trade, China has thus far been studied by using GMRIO model to estimate the environmental impact with several perspectives [114, 138].

Continuous investigation of the literature releases the fluctuation of PBE, CBE, EEE, EEI and EEB of the ECCT. Based on the equation EEB=PBE-CBE=EEE-EEI, we get the EEB of ECCT in Appendix. A. From the results, the variation of PBE and CBE has shown a big difference in 2002, the PBE is between 2,606 $\mathrm{Mt} \mathrm{CO}_{2}$ emissions and 3,620 $\mathrm{Mt} \mathrm{CO}_{2}$ emissions with the change rate of around $39 \%$, and the $\mathrm{CBE}$ in 2002 is changed from $1,841 \mathrm{Mt} \mathrm{CO}_{2}$ emissions to $4030 \mathrm{Mt} \mathrm{CO}_{2}$ emissions with a great variation rate of over 54\%. With different research motivations and 
assumptions in modeling, the EEE and EEI of ECCT are inconsistent. Especially in 2007, the EEE changed from $478 \mathrm{Mt} \mathrm{CO}_{2}$ emissions to over 3,000 $\mathrm{Mt} \mathrm{CO}_{2}$ emissions, and the EEI ranged from 140 Mt to over $1,700 \mathrm{Mt} \mathrm{CO}_{2}$ emissions. Moreover, the EEB varied between over $100 \mathrm{MtCO}_{2}$ emissions and over 2,900 $\mathrm{Mt} \mathrm{CO}_{2}$ emissions dramatically.

Uncertainties from methodological selection, assumption, data sources and data processing existing within ECCT evaluation process should be reduced in the further study. The technology assumption during emission calculation could contribute some biases to the estimation. For instance, in the earlier literature, some imported goods could be assumed having the same production technology with the domestic goods. However, some was divided into the two parts that used in intermediate input and final demand domestically in the imported country. In fact, the real situation are some exported goods are produced totally domestically, some are produced jointly by imported goods and domestic inputs, and some are produced by re-imported intermediate goods mixed with domestic inputs. Therefore, it's a challenge to distinguish different sourced trade goods and service flows in model design on calculating the carbon emissions.

It is urgent to overcome the uncertainties on data collection during estimation in further study for more reliable policies on carbon abatement based on carbon evaluation in China. High-quality database on China's national and regional data should be collected and released with low discrepancies. Particularly, it is necessary to avoid inconsistencies between the aggregated regional and national Input-output data and energy intensity as well as the gap among China's domestic IO data and other available database (for example, WIOD, OECD and Eora). For example, recently a new tendency in ECCT study is to consider the differentiation lying in China's regional economy, energy use structure, and carbon intensity to more effective carbon control policies in region (province or city) level in China [147, 150]. The estimate of regional ECCT can describe the regional carbon flows between China and her trade partners (as well as regional carbon flows in China) which would be benefit to allocate regional carbon responsibility and fulfill China's carbon mitigation target effectively whilst make some possibilities on international carbon mitigation. However, the prerequisite is to build a new database with different sourced databases with purposed policy consideration.

The different considerations on sector classification among different database should be 
considered when China's regional or national data need to be merged into other database which should be based on more identified data sources. For example, to our knowledge, there are some variations between China's aggregated national IO data aggregated by her regional IO data and official national IO data. For example, the discrepancies existed in the aggregated sectoral inputoutput data and sectoral energy use resulted from different assumption on the original sectoral design and energy use categories. Moreover, the discrepancies are vast among current available databases. Some discrepancies also could be tested between China's input-output data in WIOD and National Bureau of Statistics from China when we try to merge China's regional IO data into WIOD database. The consistency of the sectoral total output and its energy intensity in different database should be avoided by comparing and adjusting among different database in further research for globalized studying the energy and carbon flows embodied in trade flows.

Recently the building of the inter-country and inter-regional input-output table could show more linkage between sectors, regions, and cities between trade partners [157]. From the current of this tendency, it could be found that scholars tends to divide China into pieces by different consideration and merge them with other countries, for example, the transnational interregional input-output table for China, Japan and Korea in 2015 by IDE-JETRO (by region, The data are available at http://www.ide.go.jp/English/Data/Io/index.html), inter-country input-output (ICIO) table by OECD (by processing or non-processing trade, the data are available at http://www.oecd.org/sti/ind/input-outputtablesedition2015accesstodata.htm), and the city level multi-regional input-output table (MRIOT) produced by 185 countries and 30 Chinese regions (including four provincial municipalities) based on Eora and China's IO data [157].

New explorations on lowering uncertainties in methodology design should be focused seriously in further study. As the most popular model on estimating carbon emission, MRIO has many merits based on Leontief inverse matrix, but also some shortcomings itself. Relaxing the assumption and following the real economic activities should be the basic idea in building more reliable carbon emission assessment skeleton. One possibility is transferring linear relationships among sectors to non-linear relationships based on certain constrain to more objective estimates [158, 159]. The reality situation of the economic productivity and energy intensity factor are totally different even in one country, as a result, the environmental cost for the same quantity of certain goods are also 
different among countries. How to estimate the different carbon intensity on the basis of carbon flows internationally with different productivities from various regions or countries by using the non-linear input-output system is a challenge in this field.

Another possibility to reduce the uncertainties in methodology design is to integrate the Leontief and Ghosh model under the IO system to calculate the carbon linkage among sectors and countries. Chinese government has shown her ambitious reform in both of supply-side and demand-side, therefore, the combining of the two models from different side of the economy could show more interesting results comparing with previous studies $[160,161]$. Besides, the impact from different property (firm ownership) of the enterprises in China should be considered [24]. The producer and consumer of China's carbon emission in and out of her territory should be divided explicitly in the future work by compiling the firm level IO table in China, in hence, the carbon emission produced by foreign propertied enterprise and consumed by demand from overseas but pollution emitted in China could be distinguished from native demanded emissions.

In conclusion, given ambitious carbon emission reduction commitments (COP 21) in Paris in 2015 from 147 countries, and the establishment of Chinese carbon trading market in 2017, as well as China's 'one belt and one road' expansion strategy in her new economic plan recently [162], it is meaningful to study emission between China and her potential closed trade partners, which would imply more useful policies on regional energy cooperation and integrated carbon reduction mechanism among countries involving 'one belt and one road' economic areas in further study. As it is known to all, China's carbon emissions have been an acute topic to the global climate change. More in-depth insights on model modification and accurate estimate for carbon emission assessment would be discussed in the near future.

With the upgrade of processing trade and new trade tendency and strategies implemented in China, China's embodied carbon emission should be estimated in temporal and spatial perspectives to obtain more comprehensive carbon control measures. The firm level assessment under different ownerships for China could help to format systematic regional carbon reducing strategies; the city level assessment under the extended global MRIO model could help to reduce carbon emission internationally; and the provincial level measurement could be treated as a necessary tool to carbon trading market in China. Moreover, other important research ideas related to embodied carbon 
emission is the decomposition analysis of the changes of driving forces. From the literature, it could be concluded that the mixed temporal and spatial decomposing analysis under time series data of input-output by SDA are the prevalent module in analyzing driving forces. Finally, the large scale computer systems and big data technology should be employed to track the worldwide carbon flows

to better understand China's embodied carbon in international trade with multidimensional perspective.

\section{Acknowledgements}

The authors gratefully acknowledge the financial support from the Natural Science Foundation of China (NSFC) under grant nos. 71273026 and 71473017. Zhonghua Zhang thanks the financial support from China Scholarship Council (CSC) and valuable support from Energy Studies Institute (ESI) in National University of Singapore (NUS). We sincerely thank three anonymous referees for their precious suggestions and corrections on this manuscript. 


\section{References}

[1] IPCC. Climate Change 2013:The Physical Science Basis.Working Group I Contribution to the IPCC 5th Assessment Report-Changes to the Underlying Scientific/Technical Assessment. . 2013.

[2] IPCC. Climate Change 2014: Impacts, Adaptation, and Vulnerability. Part B: Regional Aspects. Contribution of Working Group II to the Fifth Assessment Report of the Intergovernmental Panel on Climate Change. 2014.

[3] Peters GP, Hertwich EG. $\mathrm{CO}_{2}$ embodied in international trade with implications for global climate policy. Environmental Science \& Technology. 2008;42:1401-7.

[4] Bloomberg. China's carbon emission drop for the first time since 2001. Bloonberg news.

2015;(http://www.bloomberg.com/news/articles/2015-03-13).

[5] Energy Desk. China's CO2 emissions likely fell 3\% in 2015 and that trend looks set to continue. In: http://energydesk.greenpeace.org/2016/01/19/china-emissions-likely-fell-in-2015/, editor.2016.

[6] IEA. $\mathrm{CO}_{2}$ emissions from fuel combustion-highlights, Pairs, France. 2011.

[7] Statista. The largest producers of $\mathrm{CO}_{2}$ emissions worldwide in 2014 based on their share of global $\mathrm{CO}_{2}$ emissions. 2015; (http://www.statista.com/statistics/271748/the-largest-emitters-of- $\mathrm{CO}_{2}$-in-the-world).

[8] Bloomberg. China Carbon Emissions Decline as 2014 Global CO2 Stays Flat.

In:http://www.bloomberg.com/news/articles/2015-03-13/china-s-carbon-emissions-drop-for-the-first-time-since2001, editor.2015.

[9] Liu Z. China’s Carbon Emissions Report 2015. Harvard Kennedy School: Cambridge, UK. 2015.

[10] Liu Z, Feng K, Hubacek K, Liang S, Anadon LD, Zhang C, et al. Four system boundaries for carbon accounts. Ecological Modelling. 2015;318:118-25.

[11] The White House. U.S.-China Joint Announcement on Climate Change. In: https://www.whitehouse.gov/thepress-office/2014/11/11/us-china-joint-announcement-climate-change, editor.2014.

[12] Pan J, Chen Y, Zhang H, Bao M, Zhang K. Strategic Options to Address Climate Change. Climate and Environmental Change in China: 1951-2012: Springer; 2016. p. 129-37.

[13] Climate Home. US, China to approve Paris climate deal in 2016.

In: http://www.climatechangenews.com/2016/03/31/us-china-to-approve-paris-climate-deal-in-2016/, editor.2016.

[14] Hansen J, Sato M. Regional climate change and national responsibilities. Environmental Research Letters. 2016;11:034009.

[15] Aprile AD, Davide M. Climate policy highlights: China's 13th Five-Year Plan and other recent developments. In: http://www.iccgov.org/wp-content/uploads/2016/04/2016.04.14_Seminar_Davide_DAprile.pdf, editor.2016.

[16] Karplus VJ, Rausch S, Zhang D. Energy caps: Alternative climate policy instruments for China? Energy Economics. 2016;56:422-31.

[17] China.org.cn. 13th Five-Year Plan. In: http://www.china.org.cn/china/NPC_CPPCC_2016/node_7234656.htm, editor.2016

[18] Climate Home. China will "far surpass" climate target.

In:http://www.climatechangenews.com/2016/02/24/china-will-far-surpass-2020-climate-target-says-top-envoy/, editor.2016

[19] Guo J, Zheng X, Wei C. Disaggregating energy use cap among China's provinces. Journal of Cleaner Production. 2016;127:374-86.

[20] Guan D, Liu Z, Geng Y, Lindner S, Hubacek K. The gigatonne gap in China's carbon dioxide inventories. Nature Climate Change. 2012;2:672-5.

[21] Liu Z, Guan D, Wei W, Davis SJ, Ciais P, Bai J, et al. Reduced carbon emission estimates from fossil fuel combustion and cement production in China. Nature. 2015;524:335-8.

[22] China File. How China's 13 th Five-Year plan addresses energy and the environment. 
In: https://www.chinafile.com/reporting-opinion/environment/how-chinas-13th-five-year-plan-addresses-energyand-environment, editor.2016.

[23] Zhang K, Wang Q, Liang Q-M, Chen H. A bibliometric analysis of research on carbon tax from 1989 to 2014. Renewable and Sustainable Energy Reviews. 2016;58:297-310.

[24] Liu Y, Meng B, Hubacek K, Xue J, Feng K, Gao Y. 'Made in China': A reevaluation of embodied CO 2 emissions in Chinese exports using firm heterogeneity information. Applied Energy. 2016.

[25] BP. British Petroleum, Statistical review of world energy June 2011. 2011.

[26] Ahmad N, Wyckoff A. Carbon dioxide emissions embodied in international trade of goods. OECD publishing. 2003.

[27] Davis SJ, Caldeira K. Consumption-based accounting of $\mathrm{CO}_{2}$ emissions. Proceedings of the National Academy of Sciences. 2010;107:5687-92.

[28] Lin B, Sun C. Evaluating carbon dioxide emissions in international trade of China. Energy Policy. 2010;38:61321.

[29] Pan J, Phillips J, Chen Y. China's balance of emissions embodied in trade: approaches to measurement and allocating international responsibility. Oxford Review of Economic Policy. 2008;24:354-76.

[30] Shui B, Harriss RC. The role of $\mathrm{CO}_{2}$ embodiment in US-China trade. Energy Policy. 2006;34:4063-8.

[31] Su B, Ang B, Low M. Input-output analysis of $\mathrm{CO}_{2}$ emissions embodied in trade and the driving forces: processing and normal exports. Ecological Economics. 2013;88:119-25.

[32] Su B, Ang BW. Input-output analysis of $\mathrm{CO}_{2}$ emissions embodied in trade: The effects of spatial aggregation. Ecological Economics. 2010;70:10-8.

[33] Liu X, Wang C. Quantitative analysis of $\mathrm{CO}_{2}$ embodiment in international trade: an overview of emerging literatures. Frontiers of Environmental Science \& Engineering in China. 2009;3:12-9.

[34] Sato M. Embodied carbon in trade: a survey of the empirical literature. Journal of Economic Surveys. 2014;28:831-61.

[35] Nejat P, Jomehzadeh F, Taheri MM, Gohari M, Abd Majid MZ. A global review of energy consumption, $\mathrm{CO}_{2}$ emissions and policy in the residential sector (with an overview of the top ten $\mathrm{CO}_{2}$ emitting countries). Renewable \& Sustainable Energy Reviews. 2015;43:843-62.

[36] Hawkins J, Ma C, Schilizzi S, Zhang F. Promises and pitfalls in environmentally extended input-output analysis for China: A survey of the literature. Energy Economics. 2015;48:81-8.

[37] Glanzel W. Bibliometrics as a research field a course on theory and application of bibliometric indicators. 2003;(http://nsdl.niscair.res.in/jspui/handle/123456789/968).

[38] Adenle AA, Haslam GE, Lee L. Global assessment of research and development for algae biofuel production and its potential role for sustainable development in developing countries. Energy Policy. 2013;61:182-95.

[39] Chappin EJL, Ligtvoet A. Transition and transformation: A bibliometric analysis of two scientific networks researching socio-technical change. Renewable \& Sustainable Energy Reviews. 2014;30:715-23.

[40] Du HB, Wei LX, Brown MA, Wang YY, Shi Z. A bibliometric analysis of recent energy efficiency literatures: an expanding and shifting focus. Energy Efficiency. 2013;6:177-90.

[41] Montoya FG, Montoya MG, Gomez J, Manzano-Agugliaro F, Alameda-Hernandez E. The research on energy in Spain: A scientometric approach. Renewable \& Sustainable Energy Reviews. 2014;29:173-83.

[42] Zhang L, Wang MH, Hu J, Ho YS. A review of published wetland research, 1991-2008: Ecological engineering and ecosystem restoration. Ecological Engineering. 2010;36:973-80.

[43] Fu HZ, Ho YS, Sui YM, Li ZS. A bibliometric analysis of solid waste research during the period 1993-2008. Waste Management. 2010;30:2410-7.

[44] Ferenhof HA, Vignochi L, Selig PM, Lezana AGR, Campos LMS. Environmental management systems in small and medium-sized enterprises: an analysis and systematic review. Journal of Cleaner Production. 2014;74:44-53. 
[45] Wei Y-M, Mi Z-F, Huang Z. Climate policy modeling: An online SCI-E and SSCI based literature review. Omega. 2014;(doi:10.1016/j.omega.2014.10.011).

[46] Mao G, Liu X, Du H, Zuo J, Wang L. Way forward for alternative energy research: A bibliometric analysis during 1994-2013. Renewable and Sustainable Energy Reviews. 2015;48:276-86.

[47] Lin X, Polenske KR. Input-output anatomy of China's energy use changes in the 1980s. Economic Systems Research. 1995;7:67-84.

[48] Polenske KR. Chinese economic planning and input-output analysis: Oxford University Press, USA; 1991.

[49] Hoekstra R. A complete database of peer-reviewed articles on environmentally extended input-output analysis. Towards 18th International Input-Output Conference of the International Input-Output Association (IIOA)2010. p. $20-5$.

[50] Wang Q. China has the capacity to lead in carbon trading. Nature. 2013;493:273.

[51] Liu Z, Guan D, Crawford-Brown D, Zhang Q, He K, Liu J. Energy policy: A low-carbon road map for China. Nature. 2013;500:143-5.

[52] Guan D, Klasen S, Hubacek K, Feng K, Liu Z, He K, et al. Determinants of stagnating carbon intensity in China. Nature Climate Change. 2014;4:1017-23.

[53] Vidal J, Adam D. China overtakes US as world's biggest $\mathrm{CO}_{2}$ emitter. The Guardian. 2007;19.

[54] Wang T, Watson J. China's carbon emissions and international trade: implications for post-2012 policy. Climate policy. 2008;8:577-87.

[55] Chen Z, Chen G. Embodied carbon dioxide emission at supra-national scale: a coalition analysis for G7, BRIC, and the rest of the world. Energy Policy. 2011;39:2899-909.

[56] Peters GP. Carbon footprints and embodied carbon at multiple scales. Current Opinion in Environmental Sustainability. 2010;2:245-50.

[57] Qi Y, Li H, Xu M. Accounting embodied carbon in import and export in China. China population, resources and environment. 2008;18:8-13.

[58] Qiang L. Energy and Carbon Embodied in Main Exporting Goods of China. China Industrial Economics. 2008;8. [59] Ying C, Jiahua P, Laihui X. Energy Embodied in Goods of International Trade in China: Calculation and Policy Implications. Economic Research Journal. 2008;7:003.

[60] Weber CL, Peters GP, Guan D, Hubacek K. The contribution of Chinese exports to climate change. Energy Policy. 2008;36:3572-7.

[61] Wiedmann T. A review of recent multi-region input-output models used for consumption-based emission and resource accounting. Ecological Economics. 2009;69:211-22.

[62] Wyckoff AW, Roop JM. The embodiment of carbon in imports of manufactured products: implications for international agreements on greenhouse gas emissions. Energy policy. 1994;22:187-94.

[63] Peters GP, Weber CL, Guan D, Hubacek K. China's growing $\mathrm{CO}_{2}$ emissions a race between increasing consumption and efficiency gains. Environmental Science \& Technology. 2007;41:5939-44.

[64] Weber CL, Matthews HS. Embodied environmental emissions in US international trade, 1997-2004. Environmental Science \& Technology. 2007;41:4875-81.

[65] Yunfeng Y, Laike Y. China's foreign trade and climate change: a case study of $\mathrm{CO}_{2}$ emissions. Energy Policy. 2010;38:350-6.

[66] Li Y, Hewitt C. The effect of trade between China and the UK on national and global carbon dioxide emissions. Energy Policy. 2008;36:1907-14.

[67] Chen GQ, Zhang B. Greenhouse gas emissions in China 2007: Inventory and input-output analysis. Energy Policy. 2010;38:6180-93.

[68] Leontief WW. Input-output economics: Oxford University Press; 1986.

[69] Leontief W. Sructure of the World Economy: Outline of a Simple Input-Output Formulation. The American 
Economic Review. 1974:823-34.

[70] Leontief W. Environmental repercussions and the economic structure: an input-output approach. The review of economics and statistics. 1970:262-71.

[71] Miller RE, Blair PD. Input-output analysis: foundations and extensions 2nd edition: Cambridge University Press; 2009.

[72] Miller RE, Blair PD. Input-output analysis: foundations and extensions. Prentice-Hall,Englewoor Cliffs,New Jersey. 1985.

[73] Hoekstra R. Economic growth, material flows and the environment: new applications of structural decomposition analysis and physical input-output tables: Edward Elgar Publishing; 2005.

[74] Hoekstra R, van den Bergh JC. Constructing physical input-output tables for environmental modeling and accounting: Framework and illustrations. Ecological Economics. 2006;59:375-93.

[75] Chang Y, Ries RJ, Wang Y. The embodied energy and environmental emissions of construction projects in China: An economic input-output LCA model. Energy Policy. 2010;38:6597-603.

[76] Hendrickson CT, Lave LB, Matthews HS. Environmental life cycle assessment of goods and services: An inputoutput approach: Routledge; 2010.

[77] Lenzen M. Errors in conventional and Input - Output - based Life-Cycle inventories. Journal of Industrial Ecology. 2000;4:127-48.

[78] Lenzen M, Crawford R. The path exchange method for hybrid LCA. Environmental science \& technology. 2009;43:8251-6.

[79] Suh S. Input-output and hybrid life cycle assessment. The International Journal of Life Cycle Assessment. 2003;8:257.

[80] Suh S, Nakamura S. Five years in the area of input-output and hybrid LCA. The international journal of life cycle assessment. 2007;12:351-2.

[81] Wang F, Dong B, Yin X, An C. China's structural change: A new SDA model. Economic Modelling. 2014;43:256-66.

[82] Zeng L, Xu M, Liang S, Zeng S, Zhang T. Revisiting drivers of energy intensity in China during 1997-2007: A structural decomposition analysis. Energy Policy. 2014;67:640-7.

[83] Zhang W, Wang J, Zhang B, Bi J, Jiang H. Can china comply with its 12th five-year plan on industrial emissions control: A structural decomposition analysis. Environmental Science and Technology. 2015;49:4816-24.

[84] Ang BW. Decomposition methodology in industrial energy demand analysis. Energy. 1995;20:1081-95.

[85] Hoekstra R, van den Bergh JCJM. Comparing structural decomposition analysis and index. Energy Economics. 2003;25:39-64.

[86] Ma C. A multi-fuel, multi-sector and multi-region approach to index decomposition: An application to China's energy consumption 1995-2010. Energy Economics. 2014;42:9-16.

[87] Su B, Ang B. Input-output analysis of $\mathrm{CO}_{2}$ emissions embodied in trade: the effects of spatial aggregation. Ecological Economics. 2010;70:10-8.

[88] Liu H, Liu W, Fan X, Zou W. Carbon emissions embodied in demand-supply chains in China. Energy Economics. 2015;50:294-305.

[89] Zhong Z, Huang R, Tang Q, Cong X, Wang Z. China's provincial CO2 emissions embodied in trade with implications for regional climate policy. Frontiers of earth science. 2015;9:77-90.

[90] Xia Y, Fan Y, Yang C. Assessing the impact of foreign content in China's exports on the carbon outsourcing hypothesis. Applied Energy. 2015;150:296-307.

[91] Schandl H, Hatfield-Dodds S, Wiedmann T, Geschke A, Cai Y, West J, et al. Decoupling global environmental pressure and economic growth: scenarios for energy use, materials use and carbon emissions. Journal of Cleaner Production. 2015. 
[92] Zhang Y. Provincial responsibility for carbon emissions in China under different principles. Energy Policy. 2015;86:142-53.

[93] Su B, Ang B. Multiplicative decomposition of aggregate carbon intensity change using input-output analysis. Applied Energy. 2015;154:13-20.

[94] Jianyi L, Yuanchao H, Shenghui C, Jiefeng K, Lilai X. Carbon footprints of food production in China (19792009). Journal of Cleaner Production. 2015;90:97-103.

[95] Aichele R, Felbermayr G. Kyoto and carbon leakage: An empirical analysis of the carbon content of bilateral trade. Review of Economics and Statistics. 2015;97:104-15.

[96] Zhang Y, Tang Z. Driving factors of carbon embodied in China's provincial exports. Energy Economics. 2015;51:445-54.

[97] Xie X, Cai W, Jiang Y, Zeng W. Carbon Footprints and Embodied Carbon Flows Analysis for China's Eight Regions: A New Perspective for Mitigation Solutions. Sustainability. 2015;7:10098-114.

[98] Jiang X, Liu Y, Zhang J, Zu L, Wang S, Green C. Evaluating the role of international trade in the growth of china's CO2 emissions. Journal of Systems Science and Complexity. 2015;28:907-24.

[99] Nejat P, Jomehzadeh F, Taheri MM, Gohari M, Majid MZA. A global review of energy consumption, CO 2 emissions and policy in the residential sector (with an overview of the top ten CO 2 emitting countries). Renewable and Sustainable Energy Reviews. 2015;43:843-62.

[100] Liang Q-M, Fan Y, Wei Y-M. Multi-regional input-output model for regional energy requirements and $\mathrm{CO}_{2}$ emissions in China. Energy policy. 2007;35:1685-700.

[101] Su B, Ang B. Multi-region input-output analysis of $\mathrm{CO}_{2}$ emissions embodied in trade: the feedback effects. Ecological Economics. 2011;71:42-53.

[102] IDE. Asian International Input-output table 2000. IDE Statistical Data Series No89\&90, IDE-JETRO. 2006.

[103] Kainuma M, Matsuoka Y, Morita T. Estimation of embodied $\mathrm{CO}_{2}$ emissions by general equilibrium model. European Journal of Operational Research. 2000;122:392-404.

[104] Wiedmann T, Lenzen M, Turner K, Barrett J. Examining the global environmental impact of regional consumption activities-Part 2: Review of input-output models for the assessment of environmental impacts embodied in trade. Ecological Economics. 2007;61:15-26.

[105] Wei Y-M, Zou L-L, Wang K, Yi W-J, Wang L. Review of proposals for an Agreement on Future Climate Policy: Perspectives from the responsibilities for GHG reduction. Energy Strategy Reviews. 2013;2:161-8.

[106] Lenzen M, Murray J, Sack F, Wiedmann T. Shared producer and consumer responsibility—-theory and practice. Ecological Economics. 2007;61:27-42.

[107] Marques A, Rodrigues J, Lenzen M, Domingos T. Income-based environmental responsibility. Ecol Econ. 2012;84:57-65.

[108] Su B, Huang HC, Ang BW, Zhou P. Input-output analysis of $\mathrm{CO}_{2}$ emissions embodied in trade: The effects of sector aggregation. Energy Economics. 2010;32:166-75.

[109] Xia Y, Fan Y, Yang C. Assessing the impact of foreign content in China's exports on the carbon outsourcing hypothesis. Applied Energy. 2015;150:296-307.

[110] Meng B, Zhang Y, Inomata S. Compilation, application and challenge of IDE-JETRO's International InputOutput tables. 2012;(URL:http://hdl.handle.net/2344/1203).

[111] Liu X, Ishikawa M, Wang C, Dong Y, Liu W. Analyses of $\mathrm{CO}_{2}$ emissions embodied in Japan-China trade. Energy Policy. 2010;38:1510-8.

[112] Shimoda M, Watanabe T, Ye Z, Fujikawa K. An empirical study on interdependency of environmental load and international IO structure in the Asia-Pacific region. International Input-Output Meeting on Managing the Environment, Seville, Spain2008.

[113] Boitier B. $\mathrm{CO}_{2}$ emissions production-based accounting vs consumption: Insights from the WIOD databases. 
WIOD Conference Paper, April2012.

[114] Zhao Y, Zhang Z, Wang S, Wang S. $\mathrm{CO}_{2}$ Emissions Embodied in China's Foreign Trade: An Investigation from the Perspective of Global Vertical Specialization. China \& World Economy. 2014;22:102-20.

[115] Zhang $\mathrm{H} . \mathrm{CO}_{2}$ Emission Embodied in International Trade: Evidence for China. International Journal of Economics and Finance. 2015;7:138-43.

[116] Wixted B, Yamano N, Webb C. Input-Output Analysis in an Increasingly Globalised World. OECD Science, Technology and Industry Working Papers,2006/07, OECD Publishing(http://dxdoiorg/101787/303252313764). 2006. [117] Wiebe KS, Bruckner M, Giljum S, Lutz C, Polzin C. Carbon and materials embodied in the international trade of emerging economies. Journal of Industrial Ecology. 2012;16:636-46.

[118] Nakano S, Okamura A, Sakurai N, Suzuki M, Tojo Y, Yamano N. The measurement of $\mathrm{CO}_{2}$ embodiments in international trade: Evidence from the harmonised input-output and bilateral trade database. OECD Publishing; 2009.

[119] Cui L-B, Peng P, Zhu L. Embodied energy, export policy adjustment and China's sustainable development: A multi-regional input-output analysis. Energy. 2015;82:457-67.

[120] Qi T, Winchester N, Karplus VJ, Zhang X. Will economic restructuring in China reduce trade-embodied $\mathrm{CO}_{2}$ emissions? Energy Economics. 2014;42:204-12.

[121] Wang Y, Geschke A, Lenzen M. Constructing a Time Series of Chinese Multi-region Input-Output Tables. The 22nd International Input-Output Conference, Lisbon, Portugal, 14-18 July 2014. 2014.

[122] Lenzen M, Moran D, Kanemoto K, Geschke A. Building Eora: a global multi-region input-output database at high country and sector resolution. Economic Systems Research. 2013;25:20-49.

[123] Moran D, Wood R. Convergence between the Eora, WIOD, EXIOBASE, and OpenEU's consumption-based carbon accounts. Economic Systems Research. 2014;26:245-61.

[124] Wood R, Stadler K, Bulavskaya T, Lutter S, Giljum S, de Koning A, et al. Global sustainability accountingdeveloping EXIOBASE for multi-regional footprint analysis. Sustainability. 2014;7:138-63.

[125] Ren S, Yuan B, Ma X, Chen X. The impact of international trade on China's industrial carbon emissions since its entry into WTO. Energy Policy. 2014;69:624-34.

[126] Ren S, Yuan B, Ma X, Chen X. International trade, FDI (foreign direct investment) and embodied $\mathrm{CO}_{2}$ emissions: A case study of Chinas industrial sectors. China Economic Review. 2014;28:123-34.

[127] Bruckner M. Counting $\mathrm{CO}_{2}$ emissions in a globalised world: producer versus consumer-oriented methods for $\mathrm{CO}_{2}$ accounting. 2010.

[128] Weitzel M, Ma T. Emissions embodied in Chinese exports taking into account the special export structure of China. Energy Economics. 2014;45:45-52.

[129] OECD. OECD.statextracts: http://stats.oecd.org/Index.aspx?DataSetCode=STAN_IO_GHG. 2015.

[130] Dietzenbacher E, Pei J, Yang C. Trade, production fragmentation, and China's carbon dioxide emissions. Journal of Environmental Economics and Management. 2012;64:88-101.

[131] Guo J, Zou L-L, Wei Y-M. Impact of inter-sectoral trade on national and global $\mathrm{CO}_{2}$ emissions: An empirical analysis of China and US. Energy Policy. 2010;38:1389-97.

[132] Bruckner M, Giljum S, Lutz C, Wiebe K. Consumption-based $\mathrm{CO}_{2}$ emissions and carbon leakage: results from the Global Resource Accounting Model GRAM. Proceeding for International Conference on Economic Modeling2010.

[133] Zhang Y. Scale, technique and composition effects in trade-related carbon emissions in China. Environmental and Resource Economics. 2012;51:371-89.

[134] Lynch RG. An assessment of the RAS method for updating input-output tables. Readings in Input-Output Analysis. 1986:271-84.

[135] Wiedmann DT, Network S. Development of a methodology for the assessment of global environmental impacts of traded goods and services: Environment Agency; 2009. 
[136] Andrew R, Peters GP, Lennox J. Approximation and regional aggregation in multi-regional input-output analysis for national carbon footprint accounting. Economic Systems Research. 2009;21:311-35.

[137] Peters GP, Andrew R, Lennox J. Constructing an environmentally-extended multi-regional input-output table using the GTAP database. Economic Systems Research. 2011;23:131-52.

[138] Asefi - Najafabady S, Rayner P, Gurney K, McRobert A, Song Y, Coltin K, et al. A multiyear, global gridded fossil fuel $\mathrm{CO}_{2}$ emission data product: Evaluation and analysis of results. Journal of Geophysical Research: Atmospheres. 2014;119:10,213-31.

[139] Kagawa S, Suh S, Hubacek K, Wiedmann T, Nansai K, Minx J. $\mathrm{CO}_{2}$ emission clusters within global supply chain networks: Implications for climate change mitigation. Global Environmental Change. 2015.

[140] Dietzenbacher E, Hoekstra R. The RAS structural decomposition approach. Trade, Networks and Hierarchies: Springer; 2002. p. 179-99.

[141] Dietzenbacher E, Los B. Structural decomposition techniques: sense and sensitivity. Economic Systems Research. 1998;10:307-24.

[142] Vendries Algarin J, Hawkins TR, Marriott J, Scott Matthews H, Khanna V. Disaggregating the Power Generation Sector for Input - Output Life Cycle Assessment. Journal of Industrial Ecology. 2014.

[143] Stefan Schaltegger PRB, Dr, Acquaye A, Genovese A, Barrett J, Lenny Koh S. Benchmarking carbon emissions performance in supply chains. Supply Chain Management: An International Journal. 2014;19:306-21.

[144] Andrew RM, Peters GP. A multi-region input-output table based on the global trade analysis project database (GTAP-MRIO). Economic Systems Research. 2013;25:99-121.

[145] Pei J, Meng B, Wang F, Xue J. Production sharing, demand spillovers and $\mathrm{CO}_{2}$ emissions: the case of Chinese regions in GVCs. (URL:http://hdlhandlenet/2344/140). 2015.

[146] Lenzen M, Pade L-L, Munksgaard J. CO2 multipliers in multi-region input-output models. Economic Systems Research. 2004;16:391-412.

[147] Yu S, Zhang J, Zheng S, Sun H. Provincial carbon intensity abatement potential estimation in China: A PSOGA-optimized multi-factor environmental learning curve method. Energy Policy. 2015;77:46-55.

[148] Turner K, Lenzen M, Wiedmann T, Barrett J. Examining the global environmental impact of regional consumption activities - part 1: a technical note on combining input-output and ecological footprint analysis. Ecological Economics. 2007;62:37-44.

[149] Zhao H, Zhang Q, Guan D, Davis S, Liu Z, Huo H, et al. Assessment of China's virtual air pollution transport embodied in trade by using a consumption-based emission inventory. Atmospheric Chemistry and Physics. 2015;15:5443-56.

[150] Huang G, Ouyang X, Yao X. Dynamics of China's regional carbon emissions under gradient economic development mode. Ecological Indicators. 2015;51:197-204.

[151] Zhu Y, Shi Y, Wang Z. How much $\mathrm{CO}_{2}$ emissions will be reduced through industrial structure change if China focuses on domestic rather than international welfare? Energy. 2014;72:168-79.

[152] Toh M-H. The RAS approach in updating input-output matrices: an instrumental variable interpretation and analysis of structural change. Economic Systems Research. 1998;10:63-78.

[153] Tukker A, Poliakov E, Heijungs R, Hawkins T, Neuwahl F, Rueda-Cantuche JM, et al. Towards a global multiregional environmentally extended input-output database. Ecological Economics. 2009;68:1928-37.

[154] Kline R, Mahajan A, Tingley D. Distributional Equity in Climate Change Policy: Responsibility, Capacity, and Vulnerability. 2016.

[155] Dimitrov RS. The Paris Agreement on Climate Change: Behind Closed Doors. Global Environmental Politics. 2016.

[156] Dietzenbacher E, Lenzen M, Los B, Guan D, Lahr ML, Sancho F, et al. Input-output analysis: the next 25 years. Economic Systems Research. 2013;25:369-89. 
[157] Chen G, Wiedmann T, Wang Y, Hadjikakou M. Transnational city carbon footprint networks-Exploring carbon links between Australian and Chinese cities. Applied Energy. 2016.

[158] Leontaritis I, Billings SA. Input-output parametric models for non-linear systems Part I: deterministic nonlinear systems. International journal of control. 1985;41:303-28.

[159] He X, Asada H. A new method for identifying orders of input-output models for nonlinear dynamic systems. American Control Conference, 1993: IEEE; 1993. p. 2520-3.

[160] Oosterhaven J. Leontief versus Ghoshian price and quantity models. Southern Economic Journal. 1996:750-9.

[161] Park JY. The supply-driven input-output model: a reinterpretation and extension. 2006.

[162] Kennedy S, Parker DA. Building China's 'One Belt, One Road'. Center for Strategic and International Studies Retrieved from http://csis org/public ation/building-chinas-one-belt-one-road. 2015.

[163] Huimin L, Ye Q. Carbon embodied in international trade of China and its emission responsibility. Chinese Journal of population resources and environment. 2010;8:24-31. 


\section{Figures in this manuscript}

Fig.1. The research framework of this paper

Fig.2. The timeline of publications on ECCT

Fig.3. The most productive countries on ECCT

Fig.4. The timeline of 198 ECCT articles from China

Fig.5. The methodologies of measuring ECCT in literature

Fig.6. The timeline of the main research on ECCT by using SRIO, BTIO and MRIO model

Fig.7. The PBE and CBE from major economies in 2009

Fig.8. The PBE and CBE in 1995, 2000, 2002, and 2005 from the literature

Fig.9. The EEE and EEI of ECCT from literature in 2005

Fig.10. The EEE, EEI and EEB of ECCT from literature in 2002

Fig.11. The variation of EEB from literature in 2005

Fig.12. The EEE, EEI and EEB of ECCT from literature in 2007 


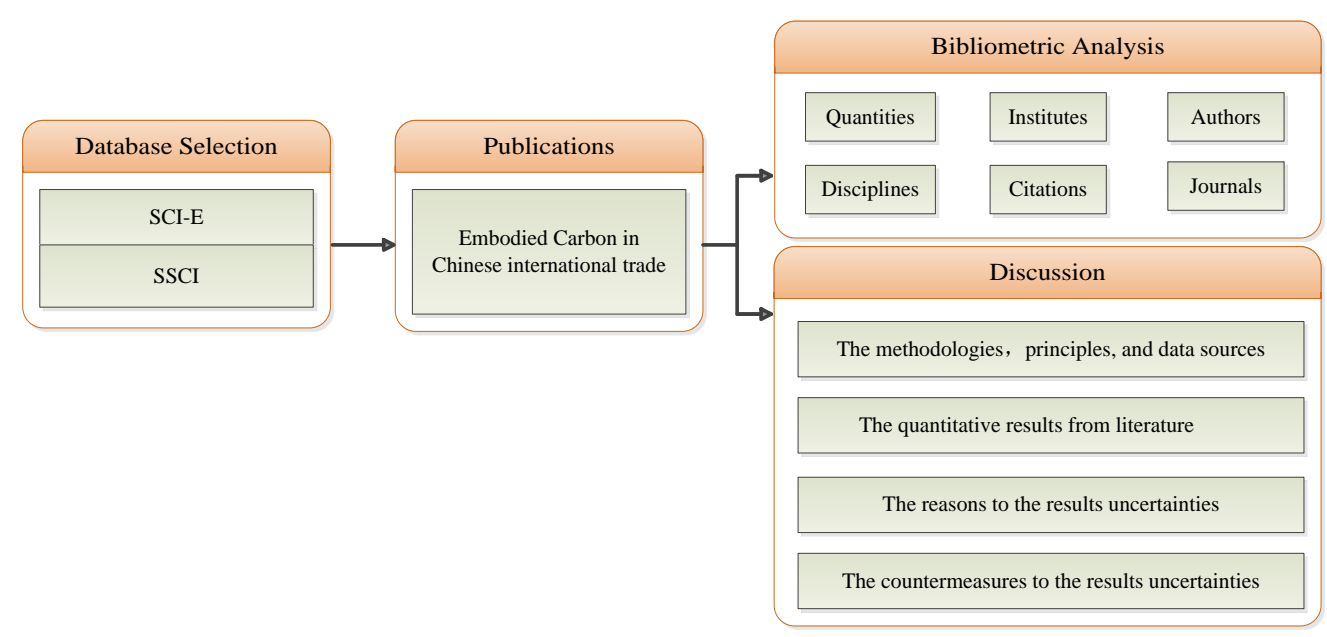

Fig.1. The research framework of this paper 


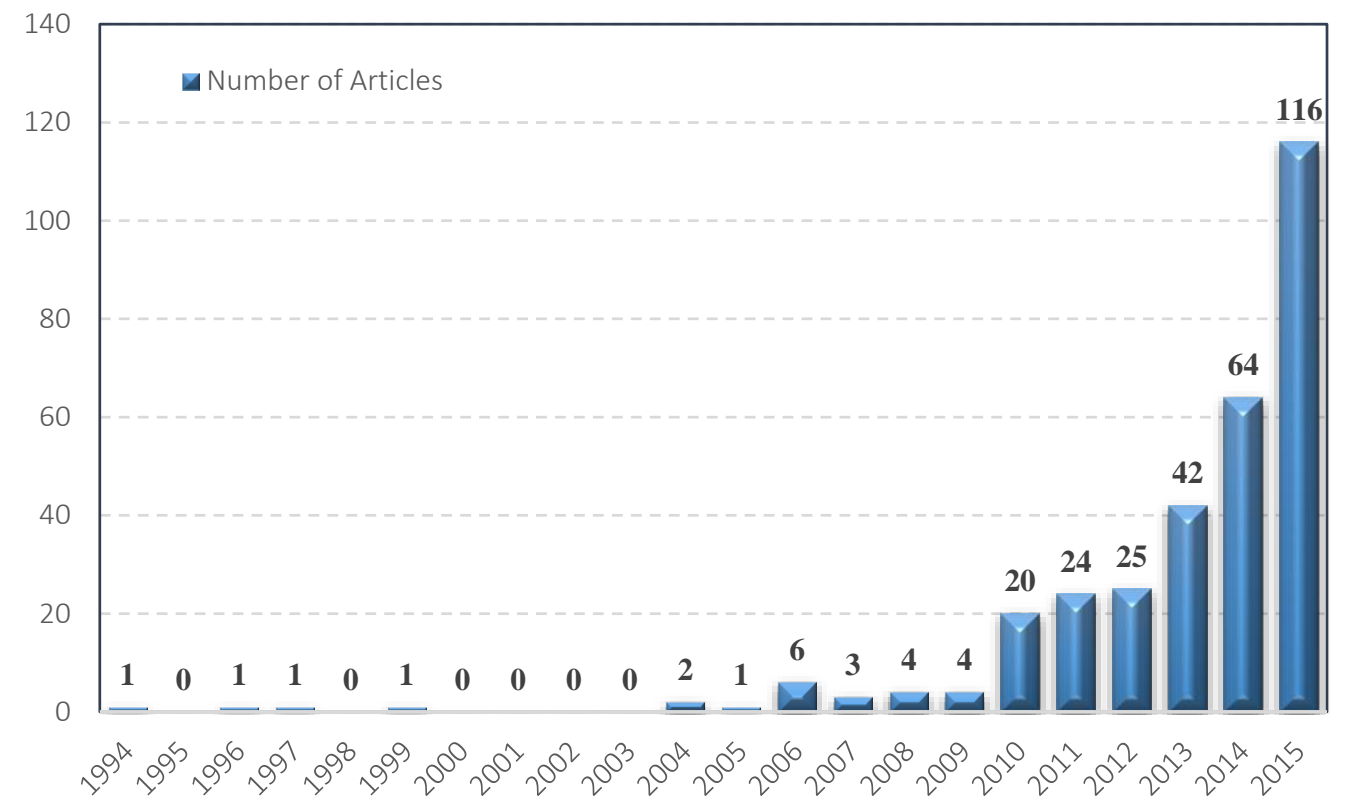

Fig.2. The timeline of publications on ECCT

Note: This figure begins in 1994 since there is no publications on ECCT during 1981-1993. 


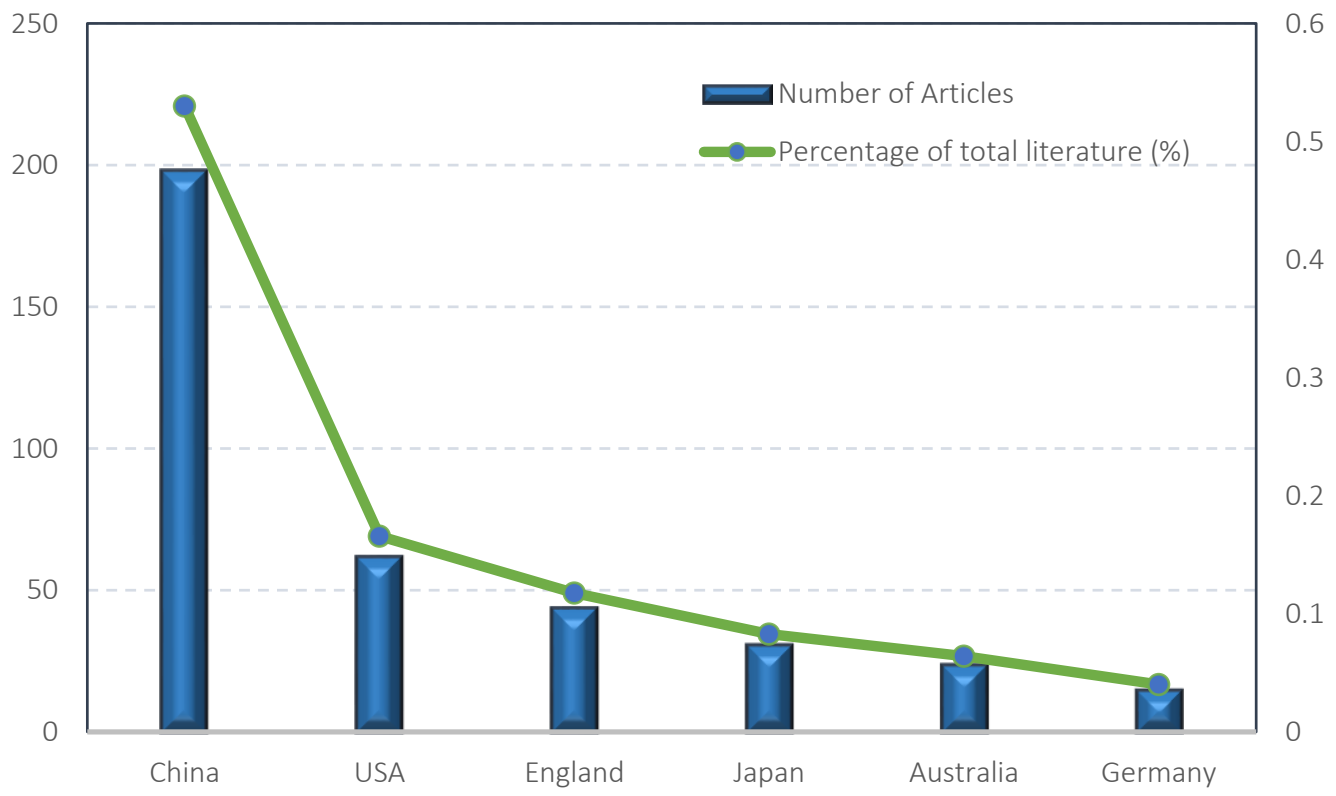

Fig.3. The most productive countries on ECCT

Note: numbers of articles and their proportions in global publications for the top six countries. 


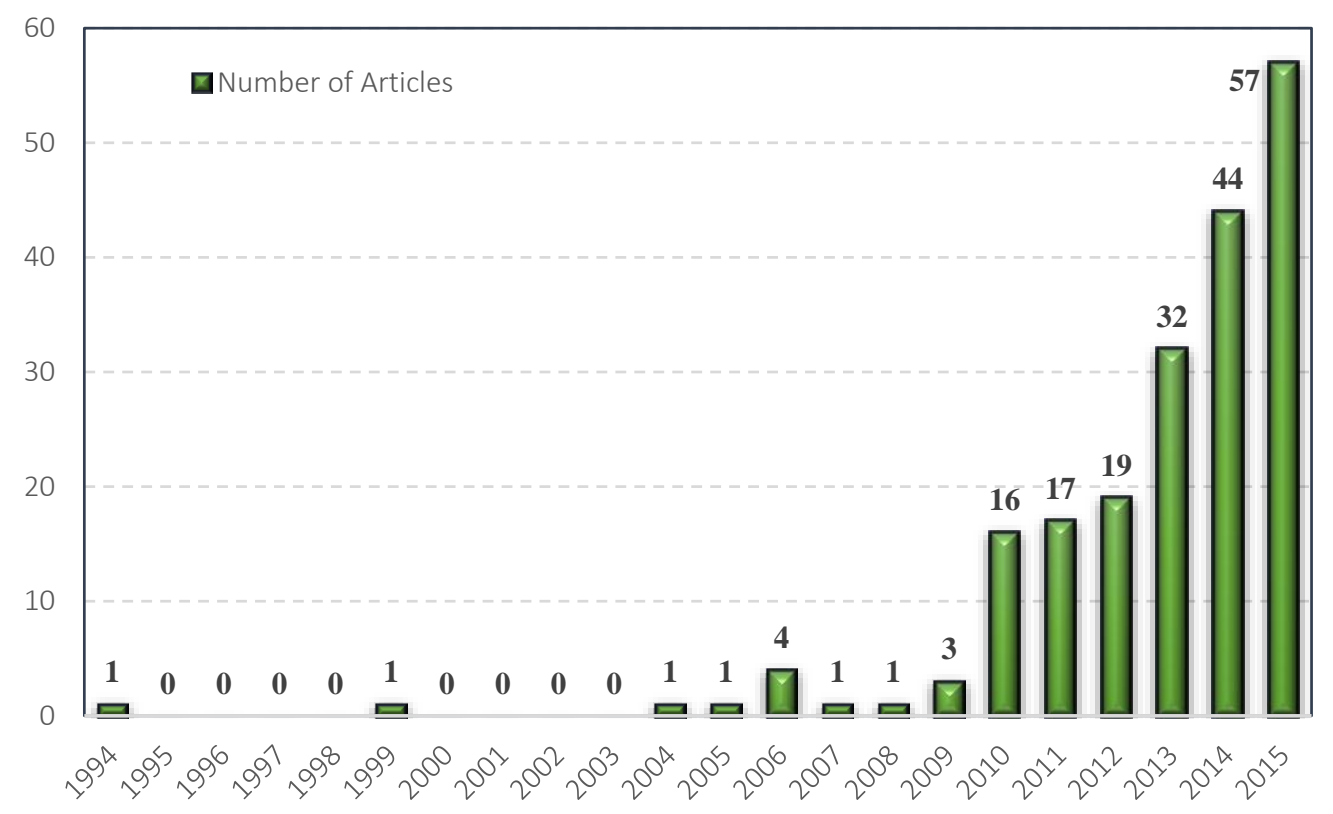

Fig.4. The timeline of 198 ECCT articles from China

Note: This figure begins in 1994 since there is no publication on ECCT during 1981-1993 and data are updated to 2015 . 


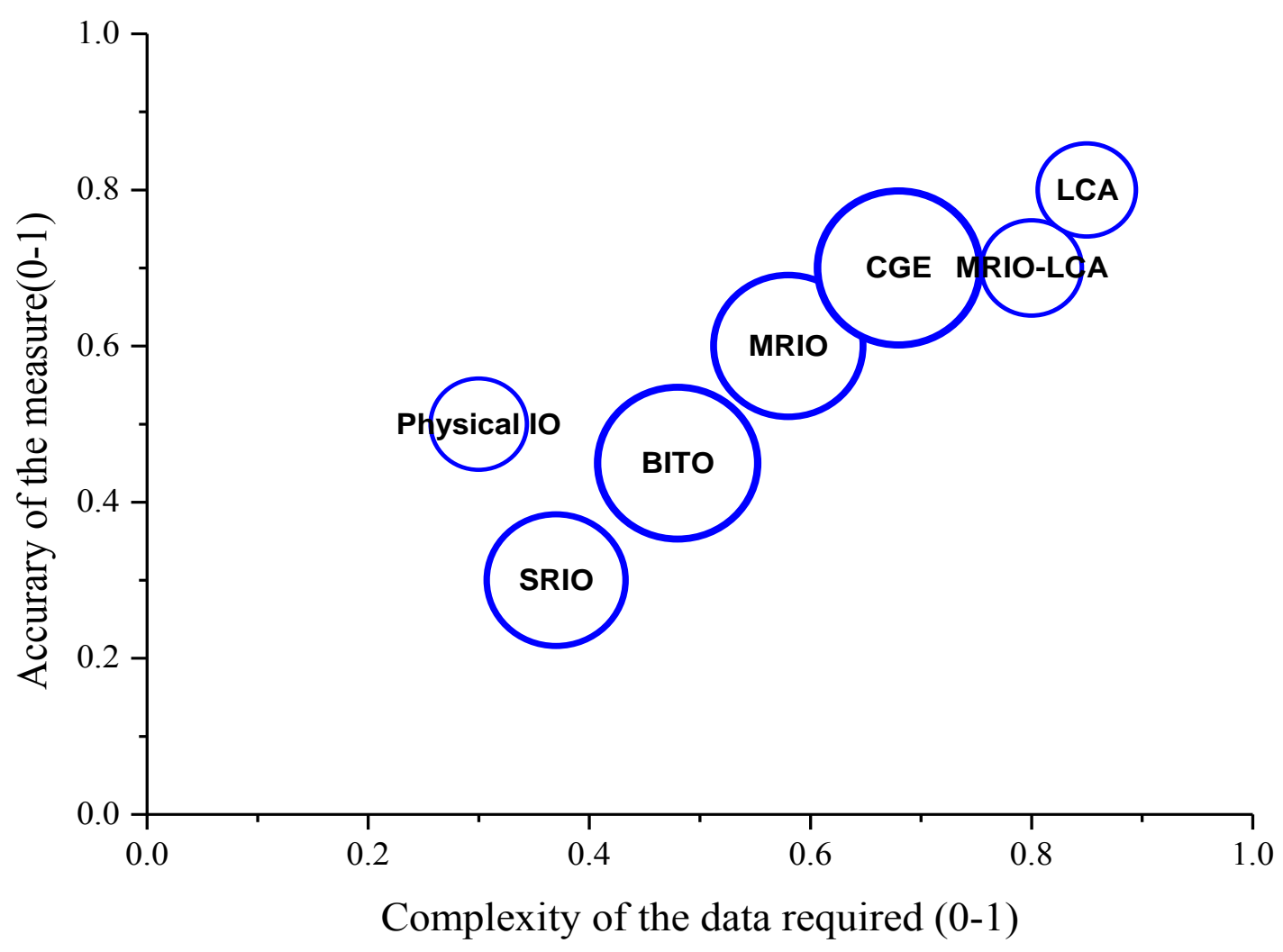

Fig.5. The methodologies of measuring ECCT in literature

Source: Authors.

Notes: The size of the circles represents the coverage of each measure relatively to the size of embodied carbon in international trade, with larger circles standing for higher coverage. The x-axis (from 0 to 1 ) corresponds to the complexity of data required to compute the measure, with lower value indicates the lower complexity of the data required, and the y-axis (from 0 to 1 ) stands for the accuracy of the results, with higher value indicates the higher accuracy of the quantitative results. 
Guan et al. (2008) Weber et al. (2008) Lin and Sun (2010a)

Yan and Yang (2010)

Shui and Harriss (2006) 'an et al. (2008) Guo et al. (2010) Huimin and Ye (2010)

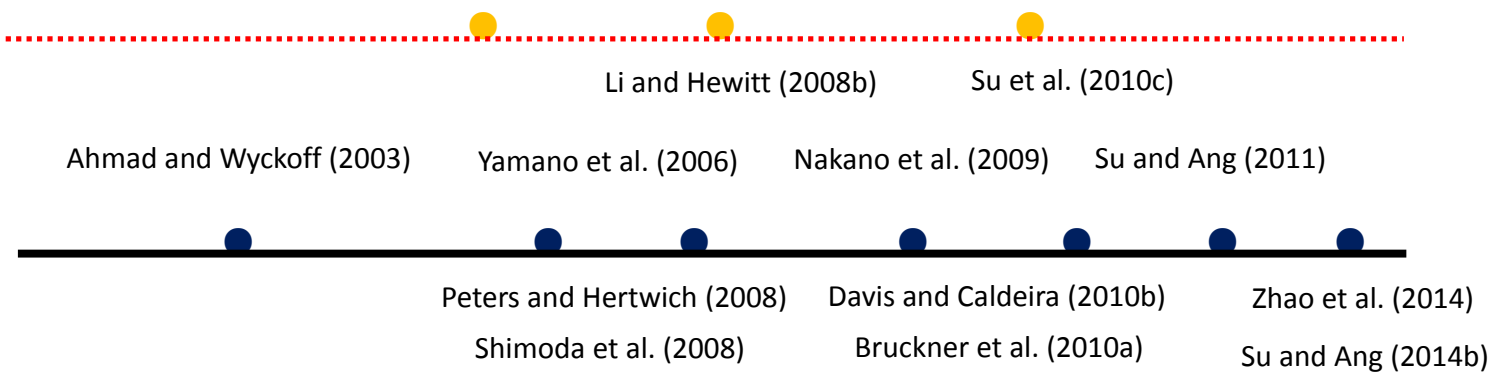

— _ . SRIO model $\quad$........... BTIO model _ MRIO model

Fig.6. The timeline of the main research on ECCT by using SRIO, BTIO and MRIO model

Notes: The primary literature on MRIO model in 2015 are as follows: Liu et al.,[88] , Liu[9], Zhong et al., [89], Xia et al.,[90], Schandl et al .,[91], Zhang [92], Liu et al., [10], Su and Ang [93]; Jianyi et al., [94], Aichele et al., [95], Zhang and Tang [96], Xie et al.,[97], Jiang et al., [98], Nejat et al., [99]. 


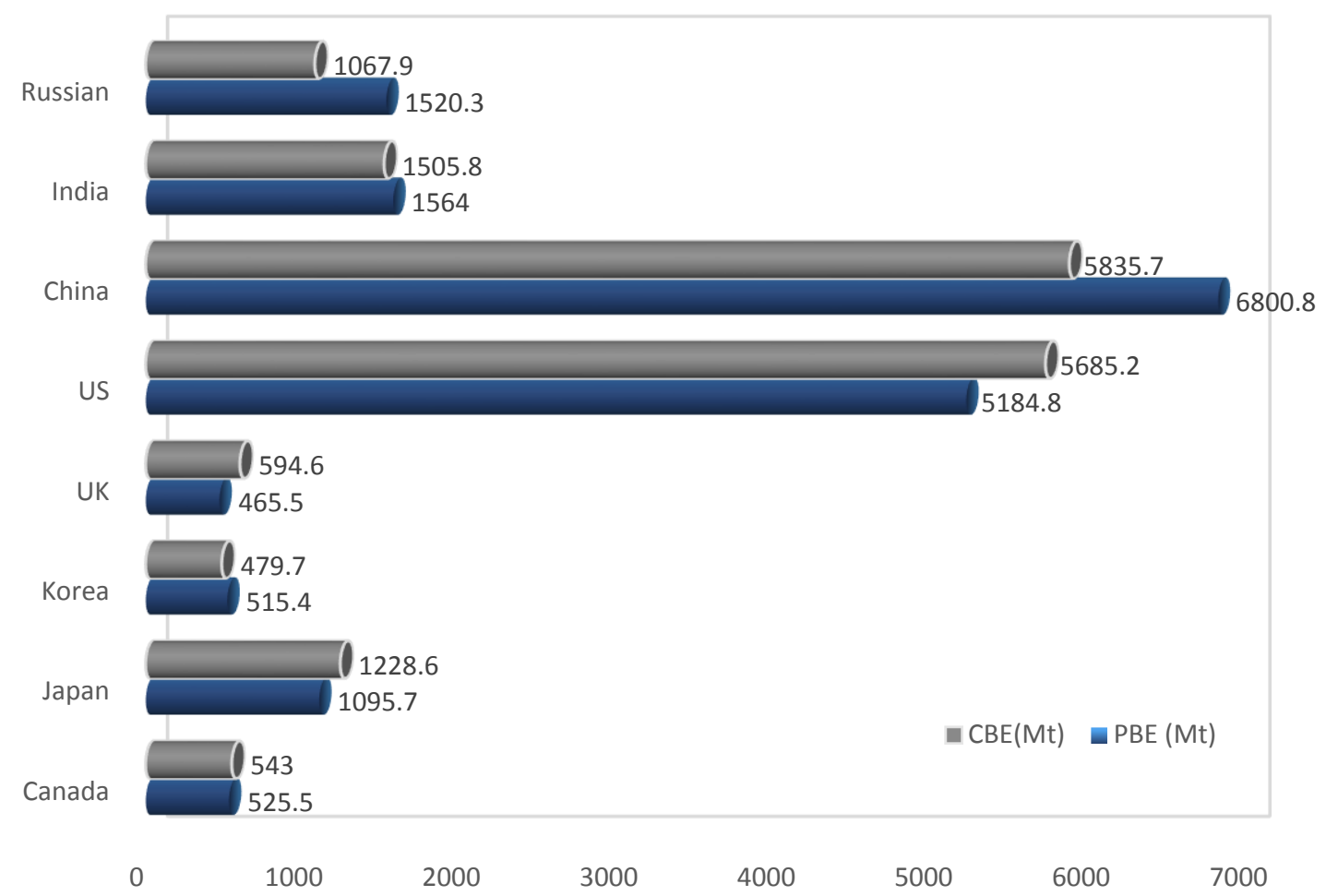

Fig.7.The PBE and CBE from major economies in 2009

Source: The data are available at: http://www.stats.oecd.org. 

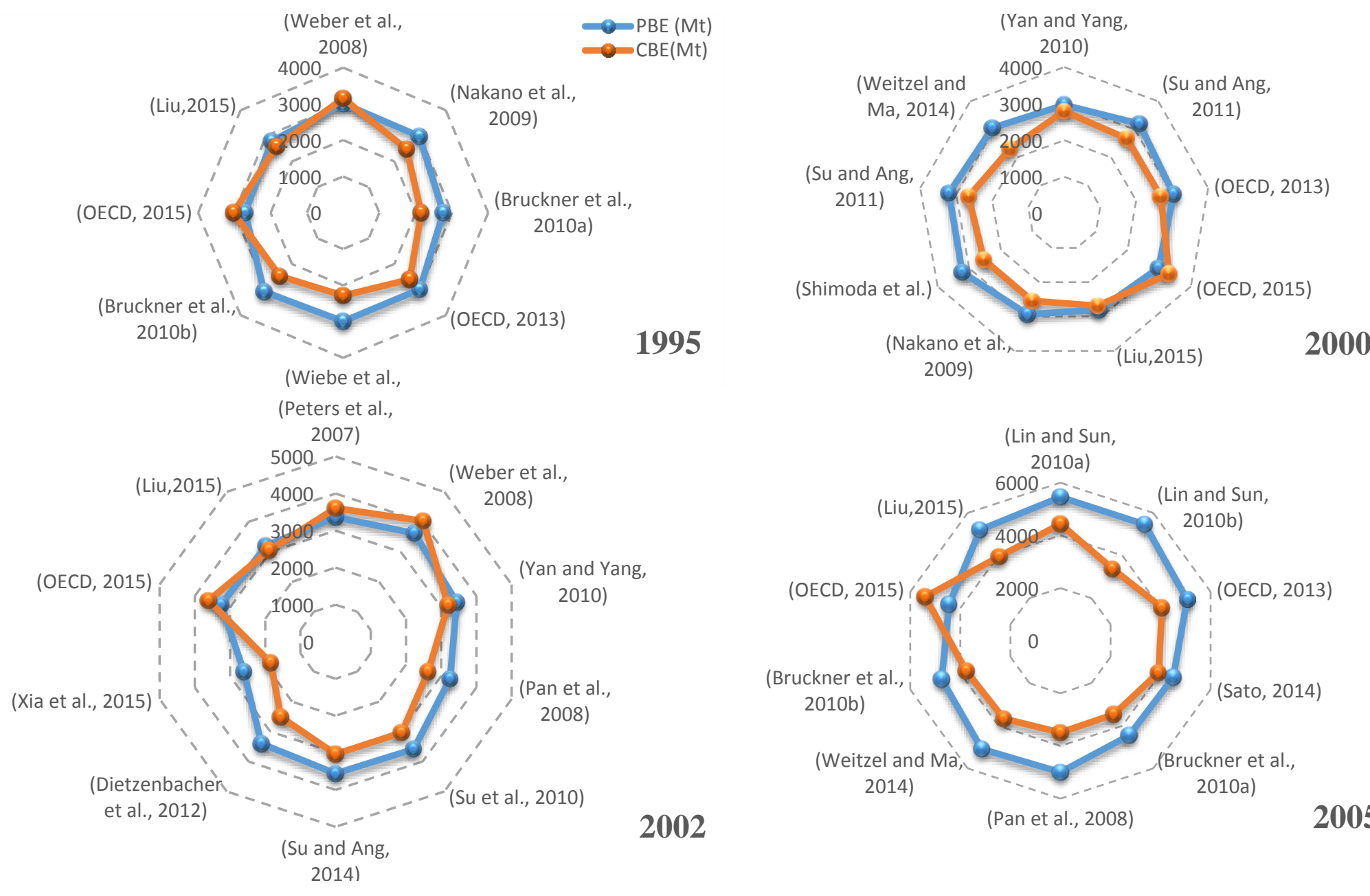

Fig.8. The PBE and CBE in 1995, 2000, 2002, and 2005 from the literature
Source: Appendix. A and supplementary information in csv file.

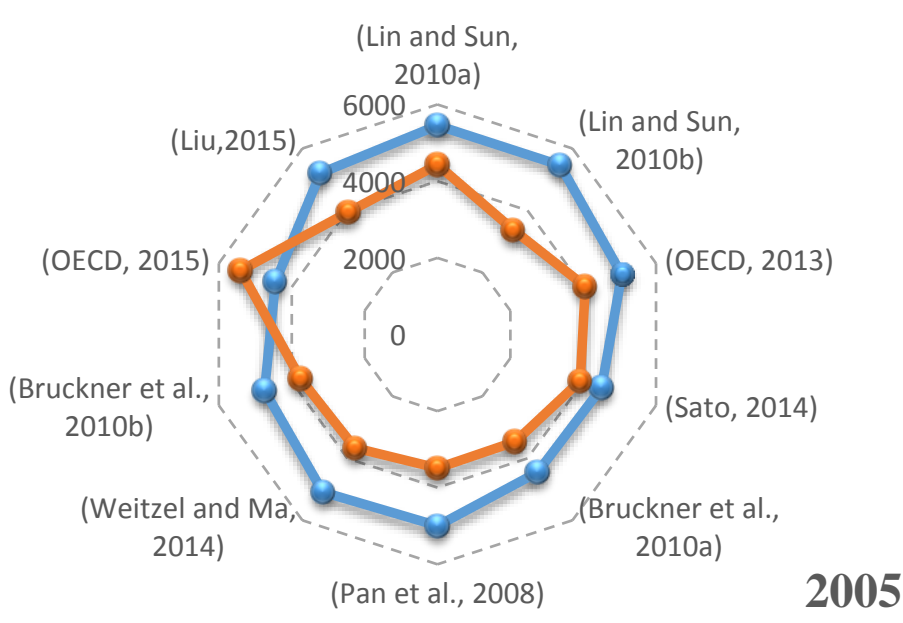




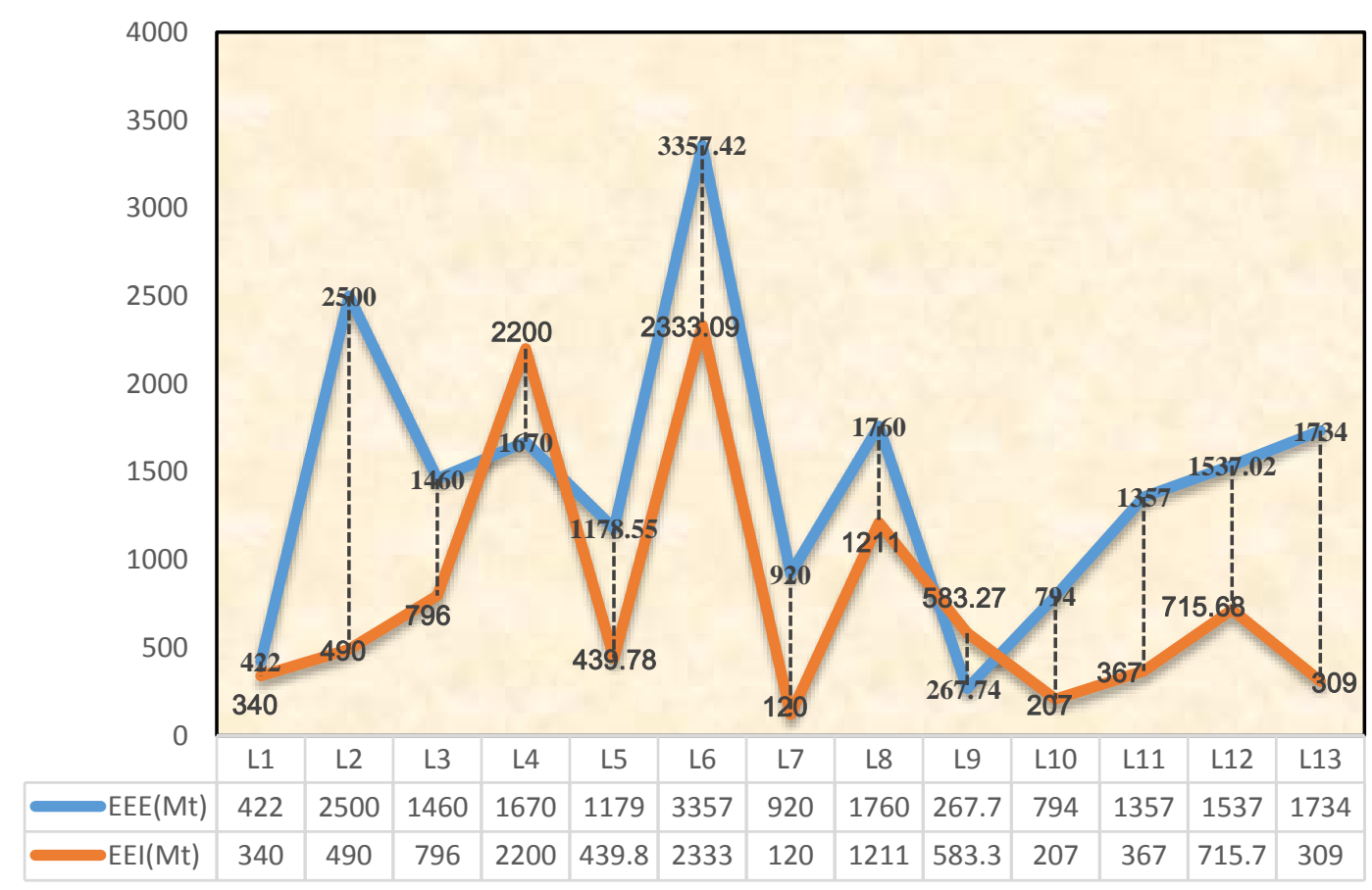

Fig.9. The EEE and EEI of ECCT from literature in 2005

Source: Appendix. A and supplementary information in csv file.

Notes: L1= (Zhang, 2012)-SRIO; L2= (Ren et al.,2014b)-SRIO; L3=(Yao et al., 2008)-SRIO;

L4=(Weber et al.,2008)-SRIO; L5=(Yan and Yang, 2010)-SRIO; L6=(Lin and Sun, 2010)-SRIO;

L7=(Ren et al.,2014)-SRIO; L8= (Huimin and Ye, 2010)-BTIO; L9= (Lin and Sun, 2010)-BTIO;

L10=(Sato, 2014)-MRIO; L11=(Bruckner et al., 2010a)-MRIO; L12=(Zhao et al., 2014)-MRIO;

L3=(Weitzel and Ma, 2014)-MRIO. 


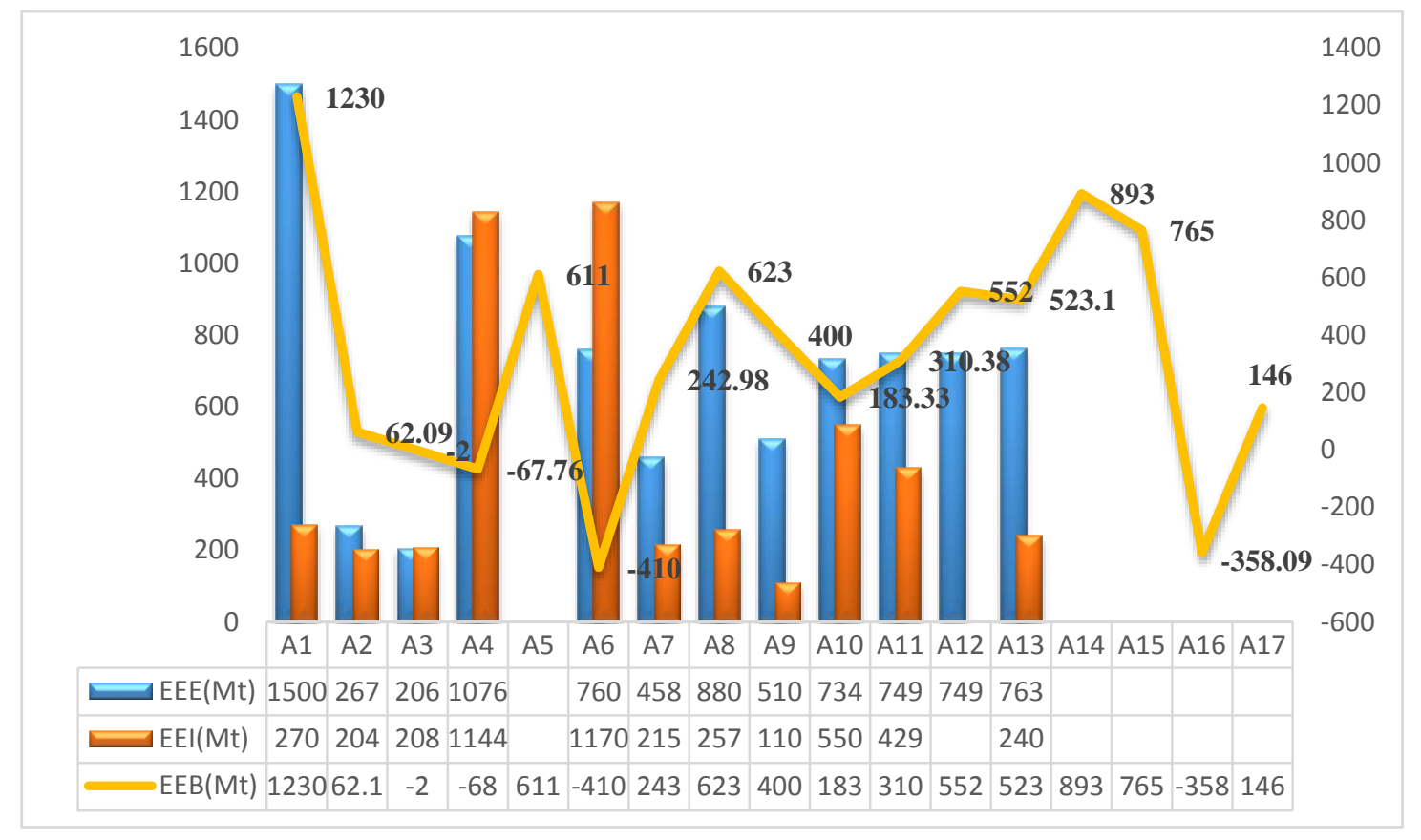

Fig.10. The EEE, EEI and EEB of ECCT from literature in 2002

Source: Appendix. A and supplementary information in csv file.

Notes: $\mathrm{A} 1=($ Ren et al.,2014b);A2= (Wei et al., 2011);A3= (Zhang, 2012);A4= (Peters et al., 2007);A5= (Qi et al., 2008);A6= (Weber et al., 2008);A7= (Yan and Yang, 2010);A8= (Pan et al., 2008);A9= (Ren et al.,2014);A10= (Huimin and Ye, 2010);A11 $=($ Zhao et al., 2014);A12 $=($ Su et al., 2010);A13= (Su and Ang, 2014);A14= (Dietzenbacher et al., 2012);A15= (Xia et al., 2015); $\mathrm{A} 16=(\mathrm{OECD}, 2015) ; \mathrm{A} 17=(\mathrm{Liu}, 2015)$. 


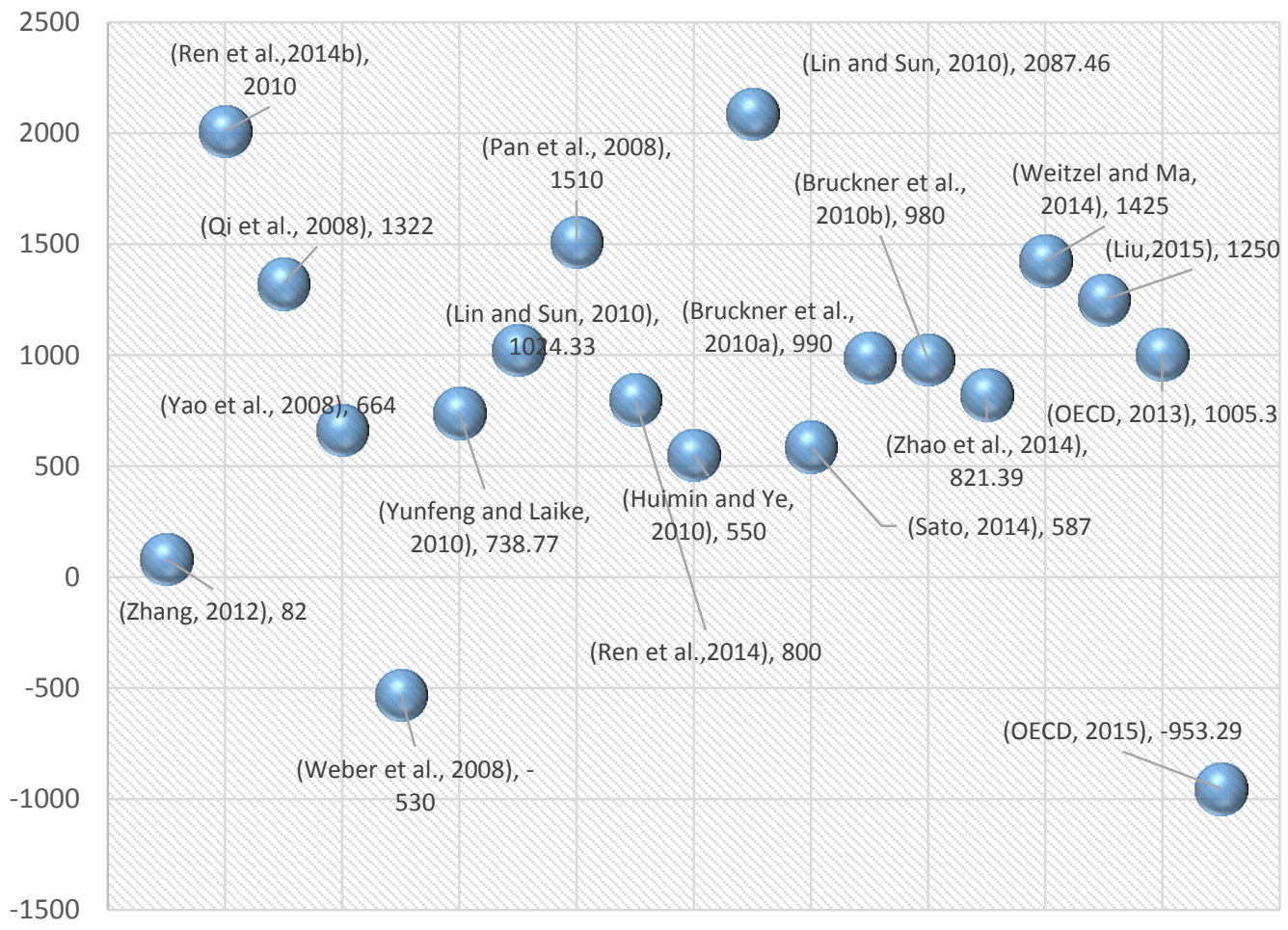

Fig.11. The variation of EEB from literature in 2005 (Mt CO2 emission)

Source: Appendix. A and supplementary information in csv file. 


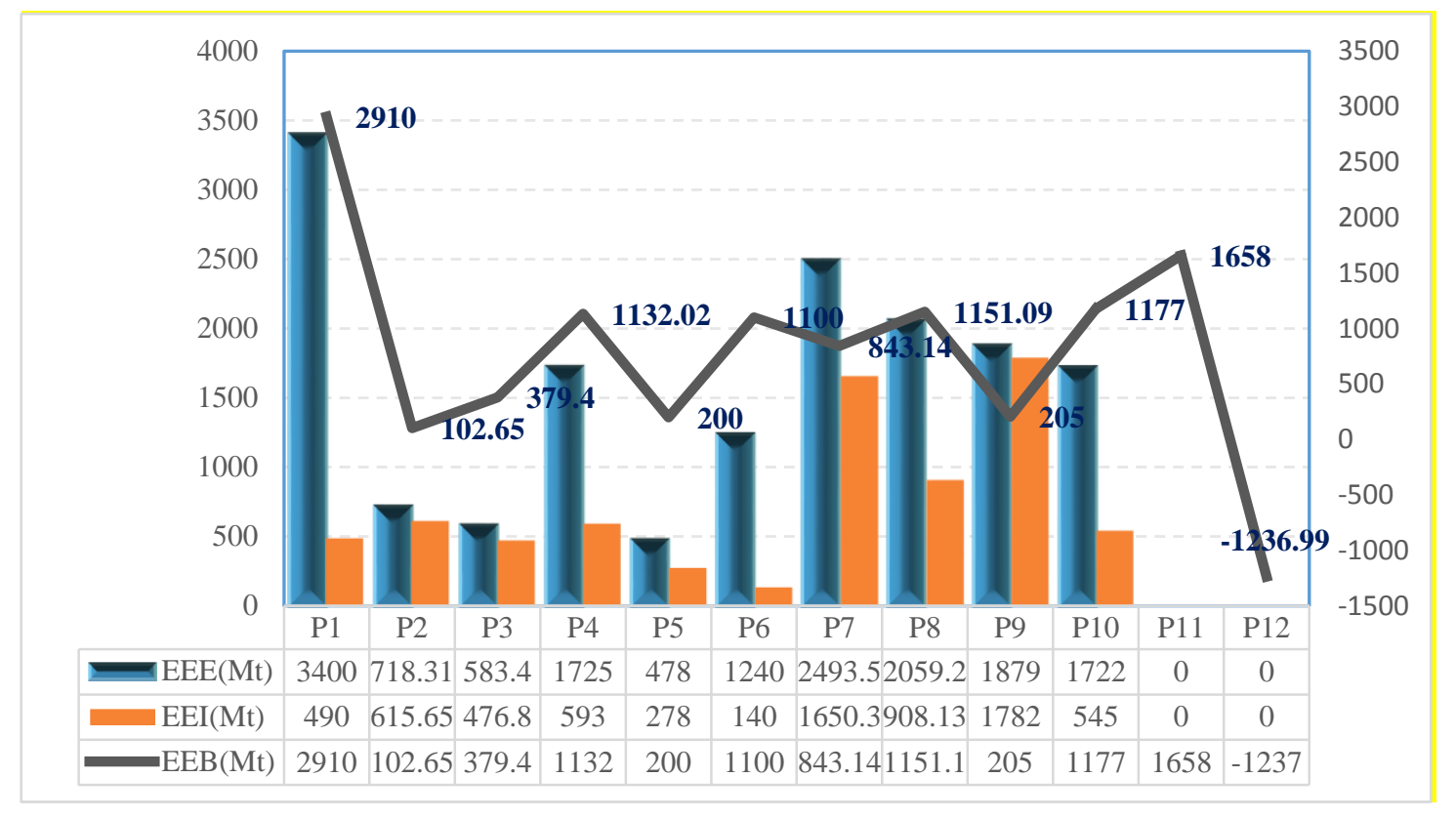

Fig.12. The EEE, EEI and EEB of ECCT from literature in 2007

Source: Appendix. A and supplementary information in csv file.

Notes: $\mathrm{P} 1=($ Ren et al.,2014b); $\mathrm{P} 2=($ Wei et al., 2011); $\mathrm{P} 3=($ Zhou and Yang, 2011); $\mathrm{P} 4=($ Yan and Yang, 2010); P5= (Zhang, 2012); $\mathrm{P} 6=($ Ren et al.,2014); $\mathrm{P} 7=($ Huimin and Ye, 2010); $\mathrm{P} 8=($ Zhao et al., 2014); $\mathrm{P} 9=($ Weitzel and $\mathrm{Ma}, 2014) ; \mathrm{P} 10=(\mathrm{Qi}$ et al., 2014); $\mathrm{P} 11=(\mathrm{Xia}$ et al., 2015); $\mathrm{P} 12=(\mathrm{OECD}, 2015)$. EEB for $\mathrm{P} 11$ and $\mathrm{P} 12$ are calculated by EEB=PBE-CBE in Appendix. A. 


\section{Tables in this manuscript}

Table 1 Top 10 journals publishing articles on ECCT

Table 2 Top 10 productive authors on ECCT

Table 3 Top 10 productive institutions on ECCT

Table 4 Highly cited articles on ECCT

Table 5 Top 6 hot disciplines on ECCT

Table 6 A brief comparison of the SRIO, BTIO and MRIO method on ECCT

Table 7 The main available input-output database including China 
Table 1

Top 10 journals publishing articles on ECCT

\begin{tabular}{llccccl}
\hline \multicolumn{1}{c}{ Journal } & $\mathrm{NA}^{a}$ & $\mathrm{P}^{b}$ & $\mathrm{IF}^{c}$ & $\mathrm{C}^{d}$ & \multicolumn{1}{c}{ Subject Categories } \\
\hline 1 & 40 & 12.62 & 3.045 & $\mathrm{UK}$ & Energy, Environmental \\
studies
\end{tabular}

Source: Authors

Notes:

${ }^{a}$ : NA is the number of articles published in current journal.

${ }^{b}: \mathrm{P}$ is the ratio of papers published in current journal out of all publications.

$c:$ IF is the impact factor in 2015.

$\mathrm{d}: \mathrm{C}$ is country that the journal being located. 
Table 2

Top 10 productive authors on ECCT

\begin{tabular}{lcccccc}
\hline & Author & $\mathrm{C}^{a}$ & $\mathrm{NA}^{b}$ & $\mathrm{NC}^{c}$ & $\mathrm{P}^{d}$ & $H$-index \\
\hline 1 & CHEN GQ & China & 26 & 575 & 22.12 & 16 \\
2 & CHEN ZM & China & 24 & 462 & 19.25 & 16 \\
3 & LI JS & China & 15 & 124 & 8.27 & 6 \\
4 & SHAO L & China & 13 & 177 & 13.62 & 8 \\
5 & GUO S & China & 13 & 106 & 8.15 & 6 \\
6 & CHEN B & China & 11 & 112 & 10.18 & 7 \\
7 & ZHANG B & China & 10 & 254 & 25.40 & 5 \\
8 & SU B & Singapore & 9 & 256 & 28.44 & 7 \\
8 & GUAN DB & England & 9 & 192 & 21.33 & 6 \\
9 & ANG BW & Singapore & 7 & 238 & 34.00 & 7 \\
\hline
\end{tabular}

Source: Authors

Notes:

${ }^{a}$ : C indicates country that the author's institution being located.

${ }^{b}$ : NA means number of articles published by this author.

$c$ : NC means total citations of the author in this field.

$d: \mathrm{P}$ is number of citations per paper.

e: H-index is based on the number of papers of one author that are collected from the total publications in this study rather than the total number of papers published by the author to investigate the productivity and influence of one author in field of ECCT. 
Table 3

Top 10 productive institutions on ECCT

\begin{tabular}{llcccc}
\hline \multicolumn{1}{c}{ Institution } & \multicolumn{1}{c}{$\mathrm{T}^{a}$} & $\mathrm{C}^{b}$ & $\mathrm{NA}^{c}$ & $\mathrm{P}^{d}$ \\
\hline \multirow{2}{*}{1} & University of Chinese Academy of & Governmental & China & 46 & 14.51 \\
& Sciences & organization & & & \\
2 & Peking University & University & China & 39 & 12.30 \\
3 & Beijing Normal University & University & China & 22 & 6.94 \\
4 & Renmin University of China & University & China & 18 & 5.68 \\
5 & Tsing Hua University & University & China & 12 & 3.79 \\
6 & National University of Singapore & University & Singapore & 9 & 2.84 \\
7 & University of Leeds & University & UK & 9 & 2.84 \\
8 & Harvard University & University & USA & 7 & 2.21 \\
9 & University of Cambridge & University & UK & 6 & 1.89 \\
10 & University of London & University & UK & 5 & 1.58 \\
\hline
\end{tabular}

Source: Authors

Notes:

${ }^{a}$ : T indicates type of institution.

${ }^{b}: \mathrm{C}$ indicates country that institution being located.

$c$ : NA means total number of articles from the current institution.

$d$ : P indicates percentage (\%) of papers published by current institution to all the literature. 


\section{Table 4}

Highly cited articles on ECCT

\begin{tabular}{lllllll}
\hline & Author & Ref. & Year & Journal & TC $^{a}$ & C $^{b}$ \\
\hline 1 & Peters and & {$[3]$} & 2008 & $\begin{array}{l}\text { Environmental science \& } \\
\text { technology }\end{array}$ & 824 & Norway \\
& Hertwich & & & 719 & USA \\
2 & $\begin{array}{l}\text { Davis and } \\
\text { Caldeira }\end{array}$ & {$[27]$} & 2010 & $\begin{array}{l}\text { Proceedings of the National } \\
\text { Academy of Science of the United }\end{array}$ & & \\
& & & & States of America & & \\
3 & Weber et al. & {$[60]$} & 2008 & Energy Policy & 464 & USA \\
4 & Ahmad and & {$[26]$} & 2003 & OECD publishing & 437 & Paris \\
& Wyckoff & & & & 410 & USA \\
5 & Shui and Harriss & {$[30]$} & 2006 & Energy Policy & 498 & England \\
6 & Wiedmann & {$[61]$} & 2009 & Ecological Economics & 387 & Paris \\
7 & Wyckoff and & {$[62]$} & 1994 & Energy Policy & & \\
& Roop & & & & 363 & Norway \\
8 & Peters et al. & {$[63]$} & 2007 & Environmental Science \& & & \\
& & & & Technology & 270 & USA \\
9 & Weber and & {$[64]$} & 2007 & Environmental Science \& & 214 & China \\
& Matthews & & & Technology & 208 & China \\
10 & Lin and Sun & {$[28]$} & 2010 & Energy Policy & England \\
11 & Yan and Yang & {$[65]$} & 2010 & Energy Policy & Oxford Review of Economic Policy \\
12 & Pan et al. & {$[29]$} & 2008 & 212 & & \\
13 & Li and Hewitt & {$[66]$} & 2008 & Energy Policy & & \\
\hline
\end{tabular}

Source: Authors

Notes:

${ }^{a}$ : TC is total citations indicating the times cited in Web of Science Core Collection.

${ }^{b}$ : C indicates country referring to the institution location of the first author. 


\section{Table 5}

Top 6 hot disciplines on ECCT

\begin{tabular}{llll}
\hline & Discipline & $\mathrm{NA}^{a}$ & $\mathrm{P}^{b}$ \\
\hline 1 & Environmental sociology ecology & 110 & $51.89 \%$ \\
2 & Energy fuels & 68 & $32.08 \%$ \\
3 & Business economics & 61 & $28.77 \%$ \\
4 & Engineering & 61 & $28.77 \%$ \\
5 & Science technology other topics & 12 & $5.66 \%$ \\
6 & Geology & 10 & $4.72 \%$ \\
\hline
\end{tabular}

Source: Authors

Notes:

${ }^{a}$ : NA means total number of articles from the current discipline.

${ }^{b}$ : P means percentage (\%) of papers published by the current discipline to all publications in the literature. Some articles are contained within one more disciplines, for the characteristic of interdisciplinary in the literature, by the web of knowledge, therefore the summation of the number of articles are not equal to total literature, and the summation of the percentage are over one. 


\section{Table 6}

A brief comparison of the SRIO, BTIO and MRIO method on ECCT

\begin{tabular}{llll}
\hline Criteria & SRIO & BTIO & MRIO \\
\hline Method boundary & Domestic/RoW & Domestic/partners & Global \\
Model Scale & Meso & Macro & Macro \\
Demander & Total consumption & Total consumption & Final consumption \\
Assumptions & Serious & Moderate & Relax \\
Data requirement & Low & Moderate & High \\
Data requirement for & None & Based on total & Based on \\
Bilateral trade & & demand & intermediate and final \\
& & & demand \\
Aggregation degree & Low & Low & High \\
Application scale & Single Country & Main trade partners & Worldwide \\
Complexity & Low & Moderate & High \\
Re-export & Exclude & Exclude & Include \\
Transparency & High & High & High \\
Accuracy & Low & Moderate & High \\
Feedback effects & No & Yes & Yes \\
Policy implications & Low & High & High \\
\hline
\end{tabular}

Source: Authors.

Note: Row indicates the rest of the world. 
Table. 7

The main available input-output databases including China

\begin{tabular}{|c|c|c|c|}
\hline Institution Source & $\begin{array}{l}\text { Coun } \\
\text { tries }\end{array}$ & Year (sectors) & References \\
\hline $\begin{array}{l}\text { NBS-PRC } \\
\text { (National Bureau of Statistics of the } \\
\text { People's Republic of China) }\end{array}$ & 1 & $\begin{array}{l}\text { 1987(33),1990(33),1992(33), } \\
\text { 1995(33),1997(40),2000(40), } \\
\text { 2002(122),2005(42),2007(135), } \\
2010(42), 2012(139)\end{array}$ & $\begin{array}{l}{[60,63,} \\
108,109]\end{array}$ \\
\hline $\begin{array}{l}\text { IDE-JETRO } \\
\text { (Institute of Developing } \\
\text { Economies-Japan External Trade } \\
\text { Organization) }\end{array}$ & 10 & $\begin{array}{l}1975(76), 1980(76), 1985(76), \\
1990(76), 1995(76), 2000(76), \\
2005(76)\end{array}$ & $\begin{array}{l}{[87,110-} \\
112]\end{array}$ \\
\hline $\begin{array}{l}\text { WIOD } \\
\text { (World Input-Output Database) }\end{array}$ & 40 & 1995(35)-2011(35) & {$[113,114]$} \\
\hline $\begin{array}{l}\text { OECD Database } \\
\text { (Organisation for Economic Co- } \\
\text { operation and Development) }\end{array}$ & 57 & $\begin{array}{l}\text { IO table } 1995(34)-2011(34) \\
\text { ICIO table 1995(34), 2000(34), } \\
2005(34), 2008-2011(34)\end{array}$ & [115-118] \\
\hline $\begin{array}{l}\text { GTAP } \\
\text { (Global Trade Analysis Project) }\end{array}$ & 140 & $\begin{array}{l}\text { Base year 2004(57),2007(57), } \\
2011(57)\end{array}$ & $\begin{array}{l}{[27,119,} \\
120]\end{array}$ \\
\hline $\begin{array}{l}\text { EORA } \\
\text { (The University of Sydney) }\end{array}$ & 187 & 1990(159)-2011(159) & {$[121,122]$} \\
\hline $\begin{array}{l}\text { EXIOBASE } \\
\text { (http://www.exiobase.eu/) }\end{array}$ & 43 & Base year 2000(163),2007(163) & {$[123,124]$} \\
\hline
\end{tabular}

Source: This table is partially adopted from Amador and Cabral (2014).

Notes: The NBS-PRC produced its first national IO table for China in 1987 and its first trial IO table in 1970s in 1991, and the detailed IO tables (110 sectors or more) in 1987, 1992, 1997, 2002, 2007, 
2010 and 2012 were published. Besides, the IO tables for municipalities (Beijing, Shanghai, Tianjin and Chongqing) were also released. China's domestic regional (8-region and/or 30 region) IO table compiled by NBS-PRC had been released in year of 1997, 2002, 2007, 2010 and 2012 (The data available at http://data.stats.gov.cn/). 